\title{
Evaluation of mesostructured silica materials with different structures and morphologies as carriers for quercetin and naringin encapsulation
}

\author{
Sonia Morante-Zarcero ${ }^{1}$ (D) $\cdot$ Alba Endrino $^{1} \cdot$ Natalia Casado $^{1}$ (D) $\cdot$ Damián Pérez-Quintanilla $^{1}$ (D) $\cdot$ Isabel Sierra ${ }^{1}$ (D)
}

Accepted: 13 August 2021 / Published online: 28 August 2021

(c) The Author(s) 2021

\begin{abstract}
Two mesostructured silicas with wormhole-like pore arrangement (HMS and MSU-2) were synthesized and evaluated for the first time as carriers for the encapsulation of two bioactive flavonoids (quercetin and naringin). For comparative purposes, a hexagonal mesostructured SBA-15 silica type frequently used as encapsulating support was also prepared and tested. All the materials were characterized before and after the loading with the analytes. Different silica/analyte ratios were evaluated to determine the loading and encapsulation kinetics of the different materials. Both flavonoids were successfully loaded inside the pores of the three silicas. The quercetin loading capacity of HMS was higher than SBA-15 and MSU-2 silicas, whereas for naringin SBA-15 and MSU-2 were slightly more effective. These differences could be attributed to the molecular size of the analytes and the textural properties of the different materials. Nevertheless, HMS was the silica that enabled to release the highest amount of both analytes. Thus, it could be considered a suitable carrier of these flavonoids and an alternative to other materials such as SBA-15. Moreover, the release process was performed under controlled conditions ( $\mathrm{pH} 2.0$ and 7.4) to simulate digestive conditions. Quercetin was delivered faster and more efficiently from the encapsulated at $\mathrm{pH} 2.0$, whereas no differences were observed for naringin at both pHs. Finally, the antioxidant activity of the resulting encapsulates was determined. The results obtained suggested the potential use of wormhole-like mesostructured silicas as carriers to enhance the stability and bioavailability of flavonoids, so they can be used in future food and biomedical applications.
\end{abstract}

Keywords Encapsulation · Bioactive flavonoids $\cdot$ Mesostructured silicas $\cdot$ Carrier materials $\cdot$ In-vitro release $\cdot$ Antioxidant activity

\section{Introduction}

In recent years, one of the current trends that have aroused special interest in different fields, such as the food, pharmaceutical and cosmetic industries, has been the encapsulation of bioactive compounds in order to preserve their healthpromoting effects. Among these bioactive compounds, polyphenols stand out for their many beneficial properties on health, including the prevention of several diseases as well as their well-known antioxidant, anti-inflammatory and antimicrobial properties, among others [1,2].

Flavonoids, which belong to a polyphenolic class, attract special interest due to their widespread occurrence in a large

Isabel Sierra

isabel.sierra@urjc.es

1 Departamento de Tecnología Química y Ambiental, E.S.C.E.T, Universidad Rey Juan Carlos, C/Tulipán s/n, 28933 Móstoles, Madrid, Spain number of vegetables and fruits, which can be used as a great source of these bioactive compounds [3]. In particular, quercetin is the major dietary flavonol and presents the highest antioxidant activity among flavonoids [4]. On the other hand, naringin is the predominant flavanone in grapefruit and also presents excellent free radical scavenging ability [5]. Both flavonoids, exhibit a broad-spectrum of pharmacological activities, such as anticancer, antiviral, antimutagenic and lipid peroxidation inhibitory effects [4-7]. Therefore, a suitable intake of these compounds may be associated with the prevention of cardiovascular damages and cancer risk. Nevertheless, this wide spectrum of beneficial properties is hindered because of their low solubility in water (few $\mathrm{mg} / \mathrm{L}$ ) and their low chemical stability when exposed to light, oxygen, heat or neutral and alkaline media [6-8], which limit their absorption after oral administration. Thus, the encapsulation of these compounds in supramolecular structures as nanoparticles or microparticles can be a good way to 
overcome these problems and improve their bioavailability and shelf-life.

For this reason, the development of innovative encapsulation strategies to achieve suitable carrier materials able to protect and provide controlled release of these compounds has become an interesting topic for food, pharmaceutic and cosmetic applications. In this context, natural carriers and biodegradable polymers have been extensively used for the encapsulation of antioxidant compounds due to their favourable properties such as good biocompatibility, easy design and preparation [9]. For instance, quercetin has been successfully encapsulated in proteins, liposomes, cyclodextrins and chitosan nanoparticles [10-15], whereas naringin has been encapsulated to a lesser extent in maltodextrin, cellulose and cyclodextrins [5, 16, 17]. However, these carriers usually present some shortcomings: they can easily aggregate with each other by flocculation in water, allow little control over the carrier size, have poor versatility, can be damaged by friction and present low heat tolerance [4, 18]. In contrast, inorganic materials such as silica-based nanoand micro-particles could be used as alternative carriers, as they present important advantages, like mechanical and chemical stability, biocompatibility, biodegradability and low toxicity. Furthermore, they have a controllable porosity, can release embedded agents, and are biologically inert $[4$, 19, 20]. In particular, mesostructured silicas have attracted in recent years significant interest to be used as carriers and have been successfully applied for the encapsulation of vitamins in food products, of antioxidants in dermic formulations and drug delivery with controlled release [21-31]. These materials can be promising carriers of bioactive compounds due to their multiple advantages, such as their high specific surface area, large pore volume, well defined poresize distribution, controlled particle size and morphology, excellent chemical, thermal and mechanical stability, stable aqueous dispersion, good biocompatibility and biodegradability and modifiable surface properties [32-35]. Due to their advanced properties, the application of mesostructured materials as carriers can successfully overcome some problems related to the low solubility and poor bioavailability of polyphenols [36, 37]. Thus, loading these compounds in the mesostructured silica systems can stabilize and protect them from degradation, ensuring high loading capacity.

Since the first time this type of materials appeared in 1992 [38, 39], a large number of synthetic strategies have been developed and, nowadays, a wide variety of mesostructured silicas with diverse porous structures and different morphologies have been successfully prepared [40]. In this sense, up to date, mesostructured silicas with 2D hexagonal ordered pore structure, SBA-15 and MCM-41, modified with different organic ligands have been the main mesostructured materials evaluated and applied as carriers for the encapsulation of quercetin $[8,18,41-43]$, besides mesostructured silicas with 3D pore arrangement, SBA-16 (cubic) [8] and KCC-1 (dendritic fibres) [43]. Nevertheless, to the best of our knowledge, these materials have never been used for the encapsulation of naringin. Moreover, as far as we know, despite the wide variety of mesostructured silicas with different structural properties, some of them like the ones with a wormhole-like framework, such as HMS and MSU-2, have not yet been evaluated as carriers for the encapsulation of these polyphenols. These mesostructured silicas with wormhole-like pore arrangement may present some advantages over other silicas such as SBA-15. For instance, they present mesostructures with thicker pore walls that increase their stability, and they have spherical morphology and small particle size that enable better access to the wormhole-like framework mesopores, leading to better retention of the analytes in adsorption processes [44]. Moreover, this type of mesostructured silicas also offers advantages related to its synthesis procedure. For instance, the synthesis of HMS is done at room temperature and it is $\mathrm{pH}$-independent, leading to a more robust and reproducible synthesis procedure [45]. In the case of MSU-2, this material has greater mechanical and thermal stability than other materials, and there are no micropores in its structure that may collapse at high temperatures. Therefore, higher calcination temperatures $\left(600^{\circ} \mathrm{C}\right)$, faster calcination ramps and shorter calcination times can be used during its synthesis procedure. In addition, the synthesis of these wormhole-like mesostructured silicas involve the use of low-cost, biodegradable, and non-toxic surfactant, high yields and moderate temperatures $\left(55^{\circ} \mathrm{C}\right)[46,47]$.

Hence, the aim of this work was to evaluate for the first time two mesostructured silicas with wormhole-like pore arrangement (HMS and MSU-2) as carriers to encapsulate quercetin and naringin to stabilize and protect them from degradation and improve their bioavailability. In addition, a hexagonal mesostructured silica SBA-15 was also tested for comparative purposes. All the materials were synthesized and characterized, and different parameters were optimized to evaluate their adsorption capacity and encapsulation efficiency. Moreover, the release process was evaluated under different $\mathrm{pH}$ conditions using phosphate saline buffer (PBS) and potassium chloride buffer to achieve a controlled and sustained release of the flavanols under digestive conditions, which adds significant value for future food and biomedical applications. Finally, as it has been previously reported that the encapsulation of quercetin in MCM-41 mesostructured silica improves its antioxidant efficacy [8], the antioxidant activity of the resulting quercetin and naringin encapsulates in HMS was determined by the DPPH• free radical-scavenging activity method. 


\section{Experimental}

\subsection{Chemicals and reagents}

Tetraethylorthosilicate $98 \%$ (TEOS, $\mathrm{M}=208.33 \mathrm{~g}$ $\mathrm{mol}^{-1}, \mathrm{~d}=0.934 \mathrm{~g} \mathrm{~mL}^{-1}$ ), poly(ethylene glycol)-blockpoly(propylene glycol)-block-poly(ethylene glycol) (EO20PO70EO20, Pluronic 123, $\mathrm{M}_{\mathrm{av}}=5800 \mathrm{~g} \mathrm{~mol}^{-1}$, $\mathrm{d}=1.019 \mathrm{~g} \mathrm{~mL}^{-1}$ ), dodecylamine $98 \%$ (DDA, $\mathrm{M}=185.36 \mathrm{~g}$ $\left.\mathrm{mol}^{-1}\right)$ and Tergitol $® \mathrm{NP}-9\left(\mathrm{M}=616.82 \mathrm{~g} \mathrm{~mol}^{-1}\right)$ were purchased from Sigma-Aldrich (St. Louis, MO, USA). Hydrochloric acid 35\% $\left(\mathrm{M}=6.45 \mathrm{~g} \mathrm{~mol}^{-1}, \mathrm{~d}=1.19 \mathrm{~g} \mathrm{~mL}^{-1}\right)$, ethanol (EtOH, purity grade $\geq 99.5 \%$ ), methanol $(\mathrm{MeOH}$, purity grade $\geq 99.9 \%$ ), potassium chloride extrapure grade $\left(\mathrm{M}=74.56 \mathrm{~g} \mathrm{~mol}^{-1}\right)$, potassium phosphate monobasic extrapure grade $\left(\mathrm{M}=136.09 \mathrm{~g} \mathrm{~mol}^{-1}\right)$, sodium chloride extrapure grade $\left(\mathrm{M}=58.44 \mathrm{~g} \mathrm{~mol}^{-1}\right)$, sodium hydroxide extrapure grade $\left(\mathrm{M}=40.00 \mathrm{~g} \mathrm{~mol}^{-1}\right)$ and sodium phosphate dibasic extrapure grade $\left(\mathrm{M}=141.96 \mathrm{~g} \mathrm{~mol}^{-1}\right)$ were obtained from Scharlab (Barcelona, Spain). Sodium fluoride 99\% $\left(\mathrm{M}=41.99 \mathrm{~g} \mathrm{~mol}^{-1}\right.$ ) was from Fluka (Busch, Switzerland). Water (resistivity $18.2 \mathrm{M} \Omega \mathrm{cm}$ ) was obtained from a Millipore Milli-Q-System (Billerica, MA, USA).

Quercetin (purity grade $\geq 95 \%$ ), naringin (purity grade $\geq 90 \%$ ) and 2,2-diphenyl-1-picrylhydrazyl (DPPH•, $\mathrm{M}=394.32 \mathrm{~g} \mathrm{~mol}^{-1}$ ) were supplied by Sigma-Aldrich (St. Louis, MO, USA).

The potassium chloride buffer ( $\mathrm{pH}$ 2.0) was prepared as follows: $0.466 \mathrm{~g}$ of potassium chloride were dissolved in $250 \mathrm{~mL}$ of water and the $\mathrm{pH}$ was adjusted with $\mathrm{HCl}$. For the PBS (pH 7.4), $0.5 \mathrm{~g}$ of potassium chloride, $0.6 \mathrm{~g}$ of potassium phosphate and $20 \mathrm{~g}$ of $\mathrm{NaCl}$ were weighed and dissolved in $130 \mathrm{~mL}$ of water. Then, $3.6 \mathrm{~g}$ of sodium phosphate were dissolved in $40 \mathrm{~mL}$ of water stirring with heat. Both solutions were then mixed, and the $\mathrm{pH}$ was adjusted with $\mathrm{NaOH}$ or $\mathrm{HCl}$. Finally, the volume was brought up to $250 \mathrm{~mL}$.

\subsection{Synthesis of mesostructured silica materials}

SBA-15 mesoporous silica was prepared as follows: $48.4 \mathrm{~g}$ of Pluronic 123 were dissolved in $1440 \mathrm{~g}$ of $2 \mathrm{M} \mathrm{HCl}$ solution and $360 \mathrm{~mL}$ of Milli-Q water under stirring at $35{ }^{\circ} \mathrm{C}$. Then, $102 \mathrm{~g}$ of TEOS were slowly added, and the resulting mixture was stirred at the same temperature for $20 \mathrm{~h}$. After this reaction time, the stirring was stopped, and the temperature was increased to $80{ }^{\circ} \mathrm{C}$ and maintained for $24 \mathrm{~h}$. The solid product was recovered by filtration and washed with

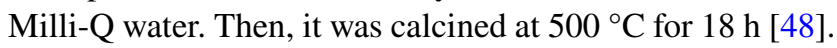

MSU-2 mesoporous silica was prepared according to Pérez-Quintanilla et al. [49]. Briefly, $78.2 \mathrm{~g}$ of Tergitol ${ }^{\circledR}$
NP-9 were mixed with $1562 \mathrm{~mL}$ of Milli-Q water. The solution was stirred at room temperature until its homogenization and, afterwards, $52.82 \mathrm{~g}$ of TEOS were added drop by drop. The resulting suspension was then aged without stirring for $20 \mathrm{~h}$. After this time, $26.4 \mathrm{~mL}$ of $0.24 \mathrm{M}$ sodium fluoride solution were added dropwise with stirring. The resulting solution was then placed in a bath under stirring at $55^{\circ} \mathrm{C}$ for $48 \mathrm{~h}$. The final product was filtered, washed with Milli-Q water and dried at $100{ }^{\circ} \mathrm{C}$ for $4 \mathrm{~h}$. Finally, the surfactant was removed by calcination at $600{ }^{\circ} \mathrm{C}$ for $12 \mathrm{~h}$.

HMS mesoporous silica was synthesized following the method described by Pérez-Quintanilla et al. [50] with slight modifications. Briefly, $30 \mathrm{~g}$ of DDA were dissolved in $388.8 \mathrm{~mL}$ of Milli-Q water and $227.4 \mathrm{~mL}$ of EtOH. The solution was stirred until its homogenization and, subsequently, $124.8 \mathrm{~g}$ of TEOS were added drop by drop. The solution was stirred for $18 \mathrm{~h}$, yielding a thick white suspension that was filtered and dried at $80{ }^{\circ} \mathrm{C}$ for $1 \mathrm{~h}$. The amine was removed by heating the solid at reflux in EtOH with a Soxhlet for $8 \mathrm{~h}$. Finally, the rest of the surfactant was removed by calcination at $550{ }^{\circ} \mathrm{C}$ for $18 \mathrm{~h}$.

\subsection{Characterization of mesostructured silica materials}

Conventional transmission electron microscopy (TEM) was achieved on a TECNAI 20 Philips microscope operating at $200 \mathrm{kV}$, with a resolution of $0.27 \mathrm{~nm}$ and $\pm 70^{\circ}$ of sample inclination, using a $\mathrm{BeO}$ sample holder. Scanning electron micrographs (SEM) and morphological analysis were performed on an XL30 ESEM Philips with an energy-dispersive spectrometry system (EDS). The samples were prepared with a sputtering method according to the following parameters: sputter time $100 \mathrm{~s}$, sputter current $30 \mathrm{~mA}$, and film thickness $20 \mathrm{~nm}$ using sputter coater BAL-TEC SCD 005. Nitrogen gas adsorption-desorption isotherms were carried out with a Micromeritics ASAP 2020 analyzer. Previous to analysis, $0.2 \mathrm{~g}$ of sample were dried in vacuum line overnight and afterwards, the samples were outgassed at $90{ }^{\circ} \mathrm{C}$ in vacuum during $10 \mathrm{~h}$ in the port of degasification of the instrument. Adsorption isotherms were measured at $-196{ }^{\circ} \mathrm{C}$ over interval of relatives pressures from $10^{-4}$ to 0.998 . Their specific surface area were determined before and after encapsulation following the Brunauer-Emmett-Teller (BET) method, the pore size distribution of the samples were determined applying the $\mathrm{BJH}$ method to the desorption branch.

\subsection{Encapsulation study of quercetin and naringin in mesostructured silica materials}

Different silica/analyte ratios (1:1, 1:5 and 5:1) were evaluated keeping constant the amount of quercetin at $50 \mathrm{mg}$. 
Thus, the loading procedure was as follows: $50 \mathrm{mg}$ of quercetin were first weighed into a $50 \mathrm{~mL}$ polypropylene centrifuge tube and $5 \mathrm{~mL}$ of EtOH were added, then the mixture was placed into an ultrasonic bath (30 s). Subsequently, the amount of silica needed for each ratio was added $(50 \mathrm{mg}$, $10 \mathrm{mg}$ and $250 \mathrm{mg}$ for 1:1, 1:5 and 5:1 silica/analyte ratios, respectively). The mixture was placed into the ultrasonic bath (1 min) and then magnetically stirred at $300 \mathrm{rpm}$ for different times $(0.5 \mathrm{~h}, 1 \mathrm{~h}, 2 \mathrm{~h}, 4 \mathrm{~h}$ and $24 \mathrm{~h})$. Afterwards, the solution mixture was centrifuged at $6000 \mathrm{rpm}$ for $8 \mathrm{~min}$. Finally, the concentration of quercetin in the supernatant was measured on a Cary $60 \mathrm{UV}-\mathrm{V}$ is Spectrometer from Agilent Technologies (Santa Clara, CA, USA) at $370 \mathrm{~nm}$. A blank solution with the same amount of silica and solvent but without the analytes was measured and used to correct the absorbance of the samples. For naringin, the same procedure as quercetin was performed, with the exception that in this case $2 \mathrm{~mL}$ of $\mathrm{MeOH}$ were used instead of $5 \mathrm{~mL}$ of $\mathrm{EtOH}$ and the concentration of naringin in the supernatant was measured at $335 \mathrm{~nm}$.

The adsorption capacity and the relative quercetin or naringin encapsulation efficiencies were calculated with the following equations:

Adsorption capacity $\left(\mu \mathrm{g} \mathrm{mg}^{-1}\right):\left(\mathrm{C}_{\mathrm{o}}-\mathrm{C}_{\mathrm{t}} \times \mathrm{V}_{\mathrm{s}}\right) / \mathrm{W}$

Encapsulation efficiency(\%): $\left(\mathrm{M}_{\mathrm{o}}-\left(\mathrm{C}_{\mathrm{t}} \times \mathrm{V}_{\mathrm{s}}\right)\right) / \mathrm{M}_{\mathrm{o}} \times 100$

where $\mathrm{C}_{\mathrm{o}}$ is the initial concentration of quercetin or naringin, $\left(\mu \mathrm{g} \mathrm{mL}^{-1}\right), \mathrm{C}_{\mathrm{t}}$ is the equilibrium concentration of quercetin or naringin, $\left(\mu \mathrm{g} \mathrm{mL}^{-1}\right)$ at time $\mathrm{t}, \mathrm{V}_{\mathrm{s}}$ is the volume of supernatant $(\mathrm{mL}), \mathrm{W}$ is the amount of silica added $(\mathrm{mg})$ and $\mathrm{M}_{\mathrm{o}}$ is the initial amount of quercetin or naringin, $(\mathrm{mg})$. All experiments were performed in triplicate $(n=3)$.

\subsection{Preliminary release studies of quercetin and naringin}

For the release of quercetin and naringin, $5 \mathrm{~mL}$ of water were added to the encapsulated sample. The solution was mixed and centrifuged at $6000 \mathrm{rpm}$ for $8 \mathrm{~min}$. The supernatant was discarded and $5 \mathrm{~mL}$ of EtOH (pH 7.0) or acidified $\mathrm{EtOH}(\mathrm{pH} 2.0)$ were added in the case of quercetin, whereas for naringin $5 \mathrm{~mL}$ of $\mathrm{MeOH}$ (pH 7.0) or acidified $\mathrm{MeOH}$ (pH 2.0) were added. The solution was sonicated for $1 \mathrm{~min}$ and then centrifugated again at $6000 \mathrm{rpm}$ for $8 \mathrm{~min}$. Finally, $10 \mu \mathrm{L}$ of the supernatant were withdrawn and analysed by UV-vis spectroscopy at $370 \mathrm{~nm}$ or $335 \mathrm{~nm}$ in the case of quercetin and naringin, respectively. A blank solution with the same amount of silica and solvent but without the analytes was measured and used to correct the absorbance of the samples.
The quercetin and naringin release efficiencies were calculated with the following equation:

Release efficiency $(\%):\left(M_{r} / M_{e}\right) \times 100$

where $\mathrm{M}_{\mathrm{r}}$ is the equilibrium amount of quercetin or naringin released at time $\mathrm{t}(\mathrm{mg}), \mathrm{M}_{\mathrm{e}}$ is the equilibrium amount of quercetin or naringin encapsulated at time $\mathrm{t}(\mathrm{mg})$. All experiments were performed in triplicate $(n=3)$.

\subsection{In vitro controlled release kinetics of quercetin and naringin encapsulated in HMS}

The in vitro release studies were carried out as follows: $5 \mathrm{~mL}$ of water were added to the quercetin or naringin encapsulates in HMS. The solution was mixed and centrifuged at $6000 \mathrm{rpm}$ for $8 \mathrm{~min}$. The supernatant was discarded and $25 \mathrm{~mL}$ of potassium chloride buffer $(\mathrm{pH} 2.0)$ or PBS $(\mathrm{pH}$ 7.4) were added and stirred at $200 \mathrm{rpm} .50 \mu \mathrm{L}$ of the mixture were withdrawn at $1 \mathrm{~min}, 5 \mathrm{~min}, 10 \mathrm{~min}, 15 \mathrm{~min}, 20 \mathrm{~min}$, $25 \mathrm{~min}, 30 \mathrm{~min}, 40 \mathrm{~min}, 50 \mathrm{~min}, 60 \mathrm{~min}, 90 \mathrm{~min}$ and $120 \mathrm{~min}$ and analysed by UV-vis spectroscopy at $370 \mathrm{~nm}$ or $335 \mathrm{~nm}$ in the case of quercetin and naringin, respectively, to quantify the amount of analyte released at each time. A blank solution with the same amount of silica and solvent but without the analytes was measured and used to correct the absorbance of the samples. The release efficiency for quercetin or naringin was calculated with Eq. 3, as described in Sect. 2.5. The release kinetics of the analytes from the pores of the HMS silica support were evaluated with the Higuchi model, in which the amount of analyte (guest) released per unit of exposed area (Q) at time $t$ can be adjusted according to the following equation:

$\mathrm{Q}=\mathrm{K}_{\mathrm{H}} \sqrt{ } \mathrm{t}$

where $\mathrm{K}_{\mathrm{H}}$ is the release rate constant for the Higuchi model. All experiments were performed in triplicate $(n=3)$.

\subsection{Quantification of quercetin and naringin}

Stock standard solutions of quercetin and naringin (1000 mg $\mathrm{L}^{-1}$ ) were prepared by diluting in $\mathrm{MeOH}$ the adequate amount of each compound and were stored at $-20^{\circ} \mathrm{C}$. Working solutions of the analytes $\left(40-20 \mathrm{mg} \mathrm{L}^{-1}\right)$ were prepared by appropriate dilution of the stock solutions with $\mathrm{MeOH}$ and were stored at $4{ }^{\circ} \mathrm{C}$. For the quantification of quercetin or naringin in the supernatant, standard curves for quercetin (with $\mathrm{EtOH}$ ) and naringin (with $\mathrm{MeOH}$ ) were prepared and analysed by UV-vis spectroscopy at $370 \mathrm{~nm}$ for quercetin and $335 \mathrm{~nm}$ in the case of naringin. Accordingly, the standard curves employed for the quantification of quercetin (0-20 mg L $\left.{ }^{-1}\right)$ and naringin $\left(0-200 \mathrm{mg} \mathrm{L}^{-1}\right)$ in the supernatant at pH 7.0 were $y=0.0607 x+0.0004\left(\mathrm{R}^{2}=0.997\right)$ and 
$y=0.006 x-0.009\left(R^{2}=0.999\right)$, respectively. On the other hand, the standard curves employed for the quantification of quercetin and naringin in the supernatant after their released at $\mathrm{pH} 2.0$ were prepared with acidified $\mathrm{EtOH}$ or $\mathrm{MeOH}$ (pH 2.0), and were $y=0.0675 x+0.005\left(\mathrm{R}^{2}=0.996\right)$ and $y=0.0061 x-0.003\left(R^{2}=0.998\right)$, respectively. In all cases, a blank solution with the same amount of silica and solvent but without the analytes was measured and used to correct the absorbance of the samples. According to this correction and the Lambert-Beer equation, all standard curves were adjusted containing the origin.

\subsection{Antioxidant activity determination by the DPPH• method}

The antioxidant activity of the analytes encapsulated in HMS mesostructured silica was determined in-vitro after their controlled release under different $\mathrm{pH}$ conditions using the DPPH• free radical-scavenging activity method [51], with some modifications. After the encapsulation procedure, the silica was washed with $5 \mathrm{~mL}$ of water, which were subsequently discarded. Then, $25 \mathrm{~mL}$ of potassium chloride buffer ( $\mathrm{pH}$ 2.0) or PBS ( $\mathrm{pH}$ 7.4) were added for the controlled release of the analytes and were stirred at $200 \mathrm{rpm}$ for $2 \mathrm{~h}$. Afterwards, $1 \mathrm{~mL}$ of the release solution (sample) was mixed with $1 \mathrm{~mL}$ of DPPH• $(0.1 \mathrm{mM})$ solution [52] and stored in the dark for $1 \mathrm{~h}$. Then, its absorbance was measured at $517 \mathrm{~nm}$. In parallel form, a blank sample was prepared for each assay by mixing $1 \mathrm{~mL}$ of potassium chloride buffer $(\mathrm{pH}$ 2.0) or PBS (pH 7.4) without containing the target analytes with $1 \mathrm{~mL}$ of the DPPH• solution and following the same incubation procedure as with the samples. The antioxidant activity was calculated as follows:

Antioxidantactivity $(\%)=\frac{A b s_{\text {blank }}-A b s_{\text {sample }}}{A b s_{\text {blank }}} \times 100$

where $\mathrm{Abs}_{\text {blank }}$ and $\mathrm{Abs}_{\text {sample }}$ are the absorbance of the blank and the sample, respectively, measured after $1 \mathrm{~h}$ of incubation with the DPPH• solution.

To determine if the encapsulation of quercetin and naringin in HMS mesostructured silica improves the antioxidant efficiency of these compounds, the antioxidant activity of non-encapsulated control samples was also evaluated. For the non-encapsulated control samples, the mg of quercetin or naringin (corresponding to the $\mathrm{mg}$ of analyte measured after its in-vitro controlled release from the carrier after $2 \mathrm{~h}$ according to the release kinetics described above in Sect. 2.6) were directly weighted and mixed at $200 \mathrm{rpm}$ for $2 \mathrm{~h}$ with $25 \mathrm{~mL}$ of potassium chloride buffer ( $\mathrm{pH} 2.0$ ) or PBS (pH 7.4). Then, $1 \mathrm{~mL}$ of this control solution was incubated in the same conditions described above and the antioxidant activity was calculated using (Eq. 5). Blank samples were also prepared in parallel for each control sample as described above.

\section{Result and discussion}

\subsection{Loading kinetics of quercetin and naringin on SBA-15, MSU-2 and HMS mesostructured silicas}

Initially, a solubility study of both analytes was carried out using $\mathrm{MeOH}$ and $\mathrm{EtOH}$, as according to the EU Commission Directives 2009/32/EC and 2010/59/EU, both solvents are authorized for the production of foodstuffs and food ingredients [53, 54]. For this purpose, an excessive quantity of quercetin or naringin $(50 \mathrm{mg})$ was added to $2 \mathrm{~mL}$ and $5 \mathrm{~mL}$ of solvent. It was observed that quercetin was not completely soluble in any of the solvents tested when $2 \mathrm{~mL}$ were used. On the other hand, with $5 \mathrm{~mL}$ of $\mathrm{EtOH}$ the amount of quercetin was completely dissolved, whereas with $\mathrm{MeOH}$ it was only partially dissolved. Conversely, naringin was completely dissolved in $2 \mathrm{~mL}$ and $5 \mathrm{~mL}$ of $\mathrm{MeOH}$, but not in EtOH. Thus, quercetin and naringin loading experiments were performed with $5 \mathrm{~mL} \mathrm{EtOH}$ and $2 \mathrm{~mL} \mathrm{MeOH}$, respectively.

Loading studies for both quercetin and naringin were carried out with the three mesostructured silicas using different silica/analyte ratios (1:1, 1:5 and 5:1) keeping constant the amount of analyte at $50 \mathrm{mg}$. Thus, the amount of silica added was the variable parameter, using $50 \mathrm{mg}$, $10 \mathrm{mg}$ and $250 \mathrm{mg}$ in each ratio, respectively. Figures 1 and 2 show the encapsulation efficiencies and adsorption (loading) kinetics obtained for quercetin and naringin using the different mesostructured silicas as carriers, respectively. In the case of SBA-15, the maximum encapsulation efficiency of quercetin was achieved at $30 \mathrm{~min}$ with the silica/analyte ratios 1:1 and 1:5 (approximately $32 \%$ ), whereas for the silica/analyte ratio 5:1 the maximum encapsulation was observed after $4 \mathrm{~h}(21 \%)$ (Fig. 1a). Thus, the ratio 5:1 seemed to be the least optimum as it provided less encapsulation, required more time and consumed more silica carrier. In contrast, the maximum encapsulation efficiency of naringin was achieved with the three ratios at $30 \mathrm{~min}$ (Fig. 1b). Nevertheless, for both analytes the silica/analyte ratio 1:5 presented higher loading ability than the other ratios (Fig. 2a and b). This is interesting because it is desirable to encapsulate the highest amount of analyte using the least amount of silica. This fact can be explained by a possible aggregation of the mesostructured silica, as described in previous works [55-57]. It is difficult to obtain these materials in monodispersive phases because they tend to form clusters or agglomerates due to the strong van der Waals interactions 
a

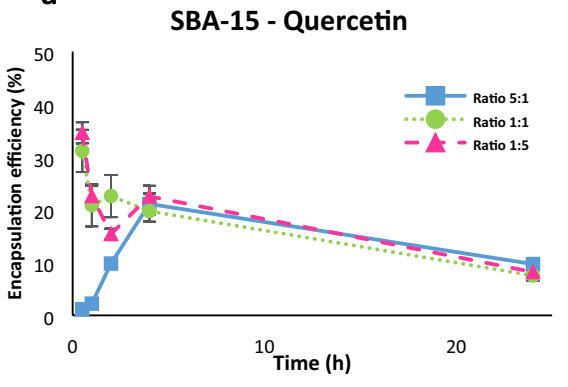

b

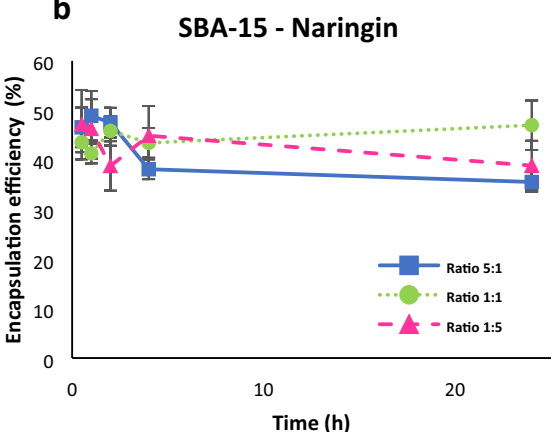

c

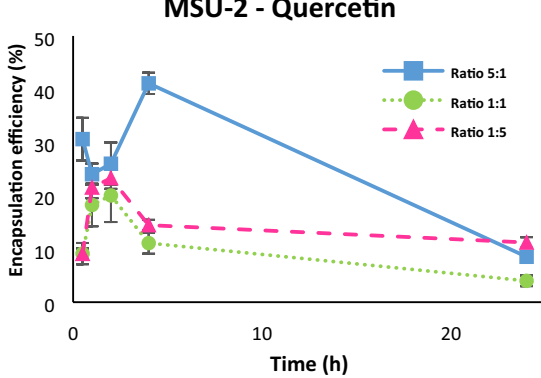

d

MSU-2 - Naringin

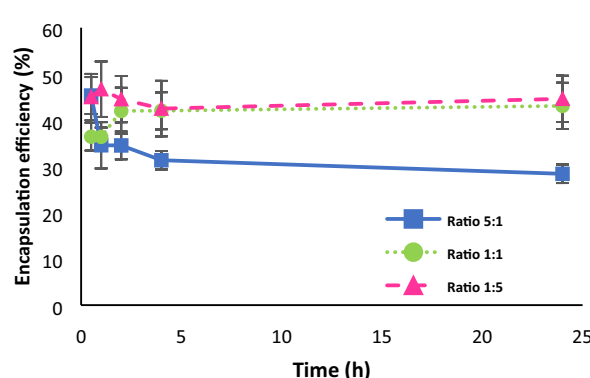

HMS - Quercetin

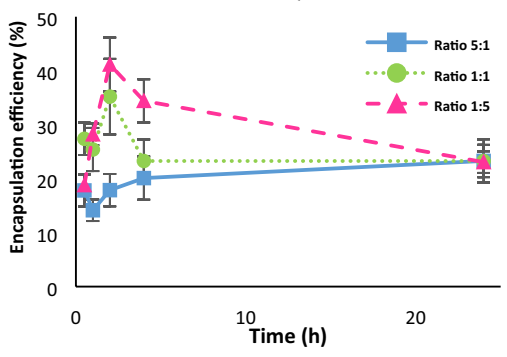

HMS - Naringin

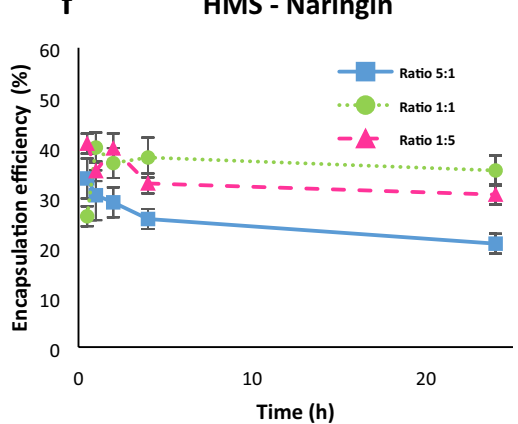

Fig. 1 Encapsulation efficiencies obtained for quercetin and naringin using different mesostructured silicas as carriers at different silica/analyte ratios. Ratio 5:1=250 mg silica/50 $\mathrm{mg}$ analyte; ratio $1: 1=50 \mathrm{mg}$ silica/50 $\mathrm{mg}$ analyte; ratio $1: 5=10 \mathrm{mg}$ silica/50 $\mathrm{mg}$ analyte
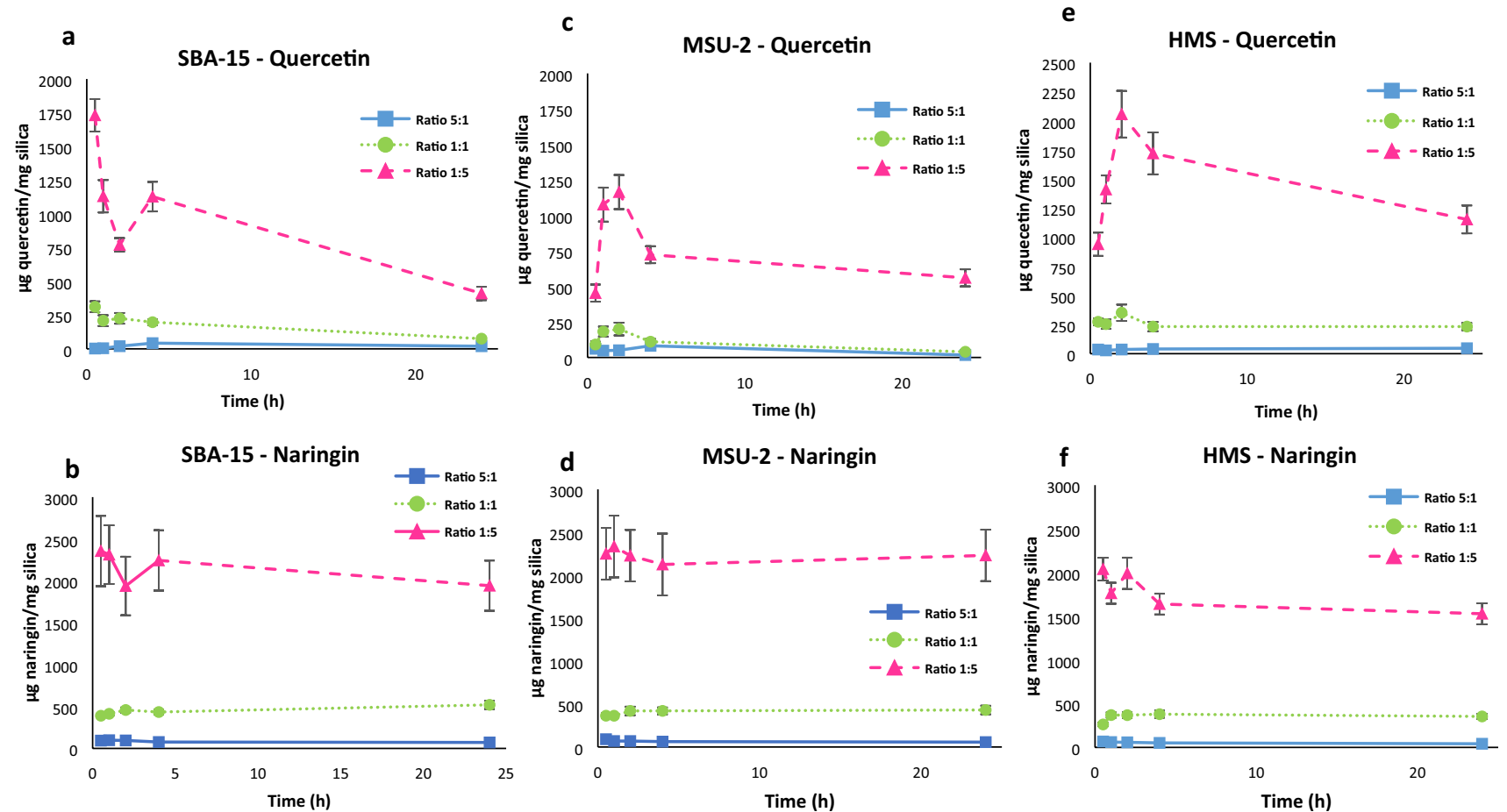

Fig. 2 Adsorption (loading) kinetics obtained for quercetin and naringin using different mesostructured silicas as carriers at different silica/analyte ratios. Ratio $5: 1=250 \mathrm{mg}$ silica/50 $\mathrm{mg}$ analyte; ratio $1: 1=50 \mathrm{mg}$ silica/50 $\mathrm{mg}$ analyte; ratio $1: 5=10 \mathrm{mg}$ silica/50 mg analyte 
[58]. Consequently, this prevents free access of the analytes to the entire surface or the entry of the pores of the material when there is a high number of silica particles in the media, which hinders the mass transfer process to the internal parts of the agglomerates. Accordingly, when the amount of mesostructured silica employed is lower, the dispersion of the material in the medium is more effective than with higher amounts of it, leading to achieve better diffusion of the analytes through the whole pore network of the silica and, therefore, showing better encapsulation efficiency, as more surface area and pores can be accessed (because less agglomerates are formed). Therefore, the silica/analyte ratio 1:5 seemed to be the most suitable for the encapsulation of quercetin and naringin in the SBA-15 mesostructured silica, as it enabled to use less amount of carrier with the best encapsulation efficiency.

On the other hand, with the MSU-2 mesostructured silica, the highest encapsulation efficiency of quercetin $(40 \%)$ was reached with the silica/analyte ratio $5: 1$ after $4 \mathrm{~h}$ of stirring (Fig. 1c). Conversely, the silica/analyte ratios 1:1 and 1:5 reached the point of maximum encapsulation after $2 \mathrm{~h}$ of stirring, but their encapsulation efficiency was significantly lower than for the silica/analyte ratio 5:1 (approximately a 20\%) (Fig. 1c). Nevertheless, despite having the highest encapsulation efficiency, the silica/analyte ratio 5:1 presented the lowest loading ability (Fig. 2c). Therefore, this was the least optimum ratio, because as the concentration of carrier increased, the adsorption capacity of MSU-2 was reduced, as explained above for SBA-15 [20, 55-58]. Regarding the other ratios, although they had similar encapsulation efficiency, the silica/analyte ratio 1:5 clearly showed higher adsorption capacity than the silica/analyte ratio 1:1 (Fig. 2c). In the case of naringin, the encapsulation efficiency was similar for the silica/analyte ratios $1: 5$ and $5: 1$, reaching the maximum point at $30 \mathrm{~min}$ and decreasing afterwards, whereas for silica/analyte ratio 1:1 the encapsulation efficiency increased with time, achieving the maximum encapsulation after $2 \mathrm{~h}$ (Fig. 1d). Despite the naringin encapsulation efficiency of MSU-2 was similar for both 1:5 and 5:1 silica/analyte ratios, the loading ability was significantly higher with the ratio 1:5 (Fig. 2d).

Regarding HMS mesostructured silica, the maximum encapsulation of quercetin was reached in all the ratios assayed after $2 \mathrm{~h}$ of stirring (Fig. 1e). The silica/analyte ratio 5:1 presented the lowest encapsulation efficiency (18\%), whereas the encapsulation efficiency was similar for both silica/analyte ratios 1:5 and 1:1 (approximately 35-40\%) (Fig. 1e). However, the adsorption capacity was clearly higher with the ratio 1:5 (Fig. 2e). On the other hand, the maximum encapsulation of naringin was observed at $30 \mathrm{~min}$ with the silica/analyte ratios 1:5 (41\%) and 5:1 (34\%), while with the ratio $1: 1$ the maximum encapsulation point was reached after $1 \mathrm{~h}$ (Fig. 1f). Regarding the adsorption capacity, it was observed that the ratio 1:5, besides the highest encapsulation efficiency, it also had the highest loading ability (Fig. 2f).

Overall, according to the results obtained for the three materials, it can be concluded that the ratio silica/analyte 1:5 seemed to be the most suitable to achieve the encapsulation of both quercetin and naringin, as it showed in all cases the highest adsorption capacity (Fig. 2). In the case of quercetin, the MSU-2 was the least effective material, as it showed the lowest encapsulation and loading efficiency. On the other hand, the SBA- 15 was the material which required less time (30 min), achieving similar encapsulation efficiency to previous works in the literature $[8,42]$. Nevertheless, despite HMS required more time $(2 \mathrm{~h})$, this material proved to have higher encapsulation efficiency of quercetin than the SBA-15 mesostructured silica (Fig. 1). Regarding naringin, all materials achieved their maximum encapsulation efficiency after 30 min. SBA-15 and MSU-2 provided similar encapsulation results (45-47\%), whereas HMS was slightly less effective but with very close values (41\%) (Fig. 1). Nevertheless, apart from the encapsulation ability, it is also important to determine the release efficiency of the material to determine which it is the most suitable to act as a carrier for the target analytes.

\subsection{Characterization of SBA-15, MSU-2 and HMS mesostructured silicas}

The materials prepared were characterized before and after the encapsulation procedure. TEM micrographs of SBA-15 showed a clear arrangement of ordered hexagonal pores with uniform size (Fig. 3a). Conversely, TEM images of MSU-2 and HMS (Fig. $3 b$ and c) confirmed the typical disordered structure of these materials, showing irregularly aligned mesopores with relatively uniform pore sizes, what it is known as wormhole-like pore arrangement. SEM pictures determined the morphology of the materials prepared. The SBA-15 had a rod-like morphology $(1 \times 0.5 \mu \mathrm{m})$ (Fig. 3d), whereas MSU-2 showed spherical particles and HMS quasispherical particles with mean diameters around $0.5-1.9 \mu \mathrm{m}$ and 1.4-5.2 $\mu \mathrm{m}$, respectively (Fig. 3e and f). These results indicate that these mesostructured silicas are microparticles, which it is interesting because due to their size they can not easily cross epitheliums or physical membranes of the body, for this reason, large particle sizes are more suitable for orally administrated controlled release devices [22, 59, $60]$. After the encapsulation procedure, it was assumed that all the materials kept the same structure, particles size and morphology as before the loading process, since it is well known that all these materials have high thermal, mechanical and chemical stability [61], even at strong $\mathrm{pH}$ media [62]. Moreover, the stability of mesostructured silicas has also been checked when a functionalization on the material has 

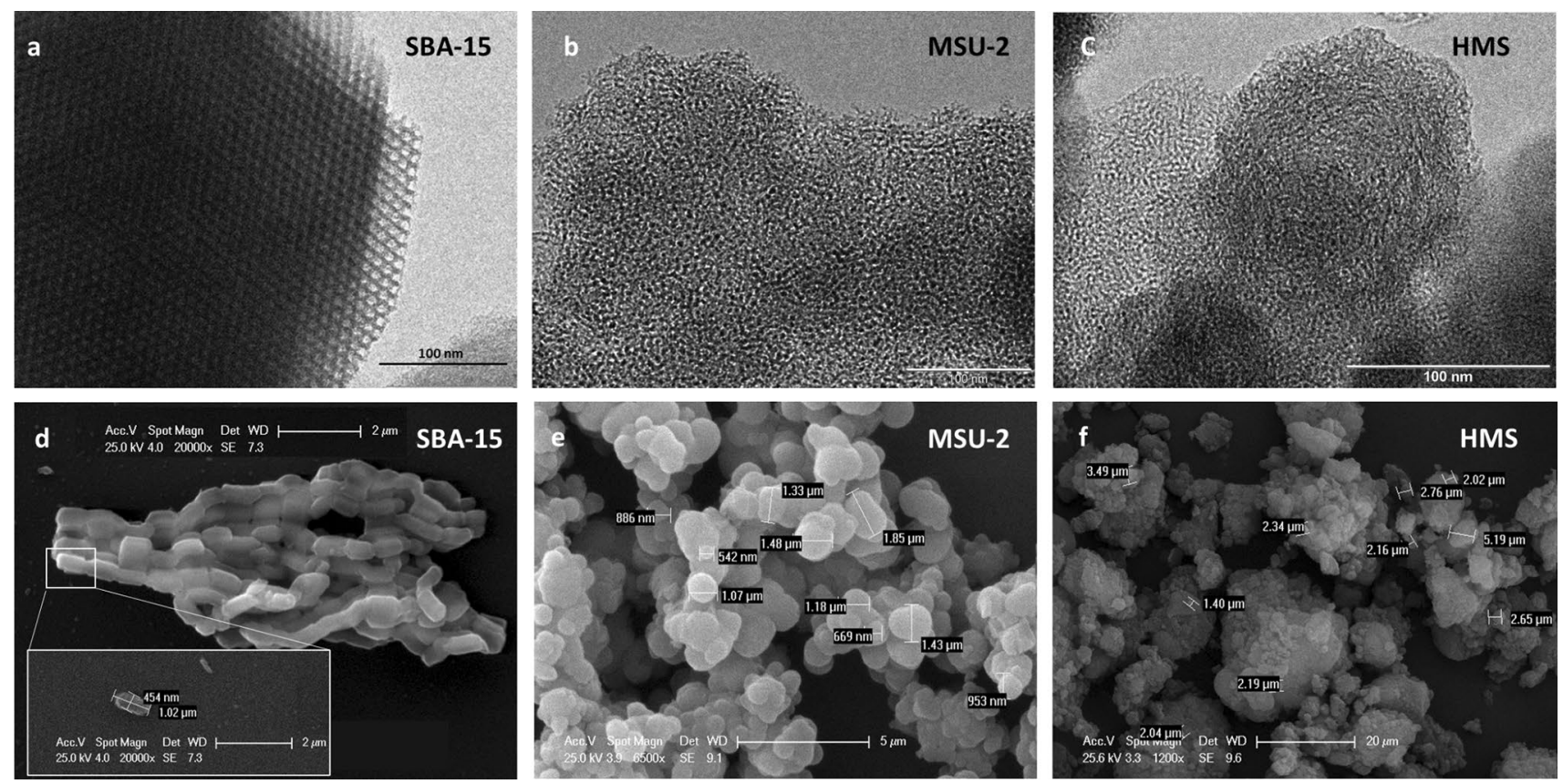

Fig. 3 TEM (a, b and $\mathbf{c})$ and SEM (d, e and $\mathbf{f})$ images of the mesostructured silicas prepared in this work

been done (which is not the case). For instance, even when large ligands like $\mathrm{C} 18$ (octadecylsilane) groups have been attached, changes in the structure of the pore size distribution have never been detected in the modified materials [63].

Nitrogen adsorption-desorption isotherms of the different mesostructured silicas non-encapsulated and encapsulated with quercetin (silica/analyte ratio 1:5) and naringin (silica/analyte ratio 1:1) are shown in Fig. 4. All the materials presented isotherms of type IV according to the I.U.P.A.C. classification with a hysteresis loop typical of mesoporous solids. SBA-15 had an H1 hysteresis loop, which corresponds to uniform cylindrical pores (Fig. 4a). On the other hand, HMS and MSU-2 had an H2 hysteresis loop (Fig. 4b and c), which indicates wormhole-like pores leading to some bottleneck effect. Both materials almost did not show a hysteresis loop as its pore size falls in the range of small mesopores being slightly smaller in the case of HMS (Fig. 4). The volume adsorbed starts to increase sharply at a relative pressure $\left(\mathrm{P} / \mathrm{P}_{0}\right)$ of 0.1 , indicating the coverage of the monolayer and the start of the multilayer filling for SBA-15, for MSU-2 and HMS this happen at a lower relative pressure, 0.04 (MSU-2) and 0.05 (HMS), at 0.45 the isotherms show a hysteresis loop what indicates capillary condensation of nitrogen within the mesopore structure at 0.45 for SBA15 and approximately 0.3 for MSU- 2 and 0.25 for HMS, (Fig. 4a, b and c). The height and steepness of the sorption step give information about the extent and uniformity of the mesoporous framework. In this sense, a tall and sharp adsorption step corresponds to a higher amount of welldefined framework mesoporosity. After the encapsulation with quercetin and naringin, all the materials kept the same trends described for their isotherms (Fig. 4a, b and c). It was observed, that after the encapsulation the volume adsorbed by the materials decreased, which was sharper in the case of quercetin than for naringin. These may indicate the uptake of the target flavonoids inside the pores. Narrow pore size distributions were found for all the materials, which confirms their uniform framework mesoporosity (Fig. 4d, e and f). SBA-15 presented the highest pore diameter (55.5 $)$ ), while MSU- 2 and HMS showed lower values ( $31.2 \AA$ and $25.2 \AA$, respectively). This may explain why the quercetin is adsorbed faster in the SBA-15 than in the other silicas. After the loading with the analytes, the pore size of all the materials barely changed, which may indicate that the pores are not blocked after the encapsulation. In the case of SBA15 part of the adsorption process could take place in the surface of the material or in the micropores, which explains the high descend experimented in the pore volume and the surface area with naringin, which size is in the range of the micropores that could lead to a partial blockage of them.

Table 1 gathers the Brunauer-Emmett-Teller surface area $\left(\mathrm{S}_{\mathrm{BET}}\right)$ and the total pore volume of the different materials before and after the quercetin and naringin loading procedure using different silica/analyte ratios (1:1 and 1:5). The materials loaded with the ratio 5:1 were not characterized, as it proved to be the relation with the lowest encapsulation efficiency for both quercetin and naringin, as previously described in Sect. 3.1. The three mesostructured silicas showed very high $\mathrm{S}_{\mathrm{BET}}$ and typical pore volume values for surfactant-assembled mesostructures [34]. Although 

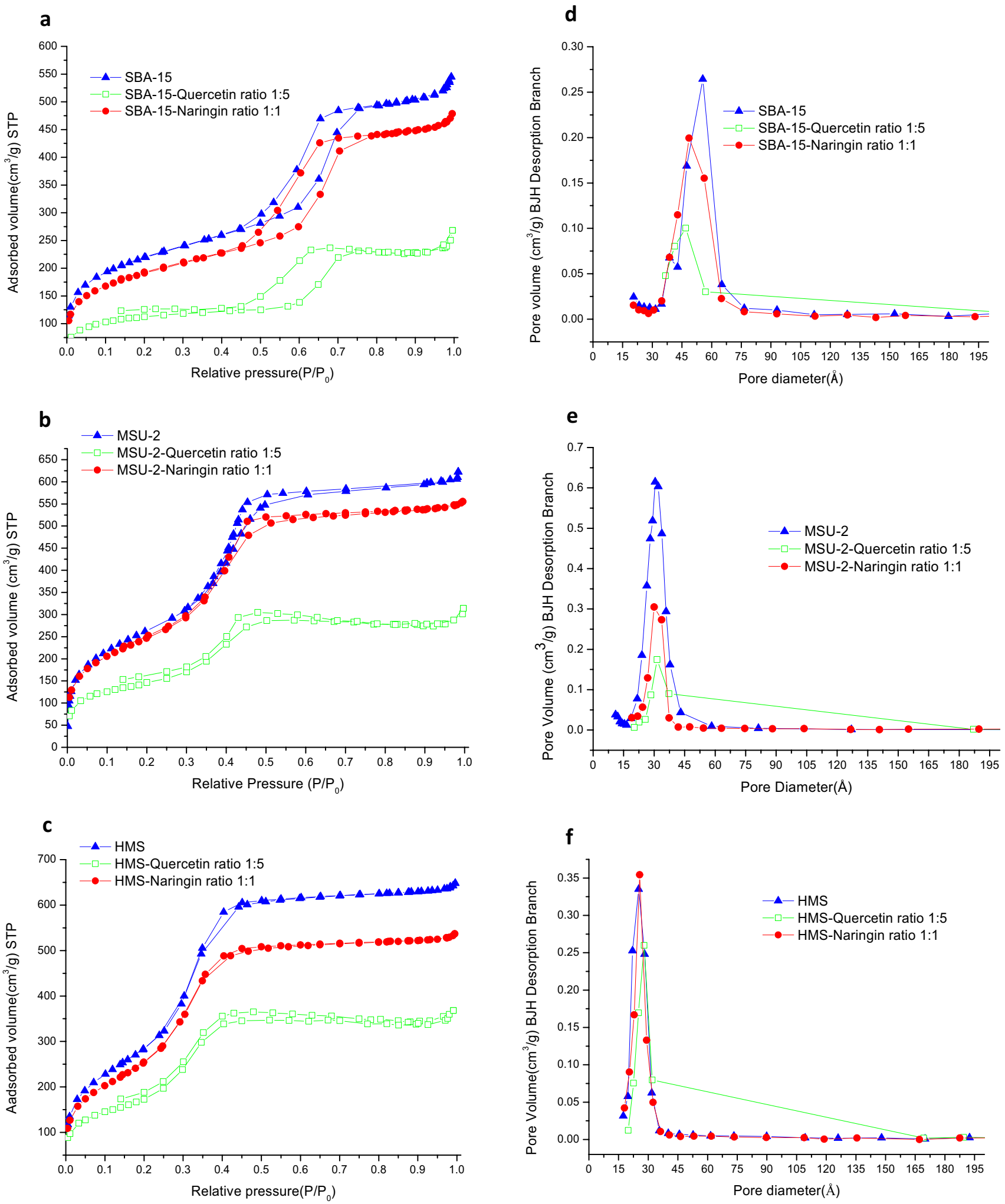

Fig. 4 Nitrogen adsorption-desorption isotherms before and after the encapsulation process with quercetin and naringin of a SBA15, b MSU-2 and c HMS and pore size distribution before and after

the encapsulation process with quercetin and naringin of $\mathbf{d}$ SBA-15, e MSU-2 and f HMS. Ratio $1: 1=50 \mathrm{mg}$ silica/50 mg analyte; ratio $1: 5=10 \mathrm{mg}$ silica/50 mg analyte 
Table 1 Textural properties of the mesostructured silicas before and after the encapsulation process

\begin{tabular}{|c|c|c|}
\hline Silica & $\mathrm{S}_{\mathrm{BET}}^{\mathrm{a}}\left(\mathrm{m}^{2} \mathrm{~g}^{-1}\right)$ & $\begin{array}{l}\text { Pore volume } \\
\left(\mathrm{cm}^{3} \mathrm{~g}^{-1}\right)\end{array}$ \\
\hline SBA-15 1D hexagonal parallel channels and rod-like particle morphology $(1 \times 0.5 \mu \mathrm{m})$ & 780 & 0.80 \\
\hline Silica-Quercetin ratio $1: 1^{*}$ & 512 & 0.58 \\
\hline Silica-Quercetin ratio 1:5* & 395 & 0.37 \\
\hline Silica-Naringin ratio $1: 1^{*}$ & 681 & 0.71 \\
\hline Silica-Naringin ratio $1: 5^{*}$ & 629 & 0.70 \\
\hline MSU-2 3D wormhole-like channels and spherical morphology $(0.5-1.9 \mu \mathrm{m})$ & 1040 & 0.99 \\
\hline Silica-Quercetin ratio 1:1 & 871 & 0.83 \\
\hline Silica-Quercetin ratio 1:5 & 519 & 0.47 \\
\hline Silica-Naringin ratio $1: 1$ & 901 & 0.84 \\
\hline Silica-Naringin ratio 1:5 & 944 & 0.89 \\
\hline HMS 3D wormhole-like channels and quasi-spherical morphology $(1.4-5.2 \mu \mathrm{m})$ & 1050 & 0.98 \\
\hline Silica-Quercetin ratio 1:1 & 873 & 0.71 \\
\hline Silica-Quercetin ratio 1:5 & 621 & 0.54 \\
\hline Silica-Naringin ratio $1: 1$ & 933 & 0.82 \\
\hline Silica-Naringin ratio 1:5 & 926 & 0.84 \\
\hline
\end{tabular}

${ }^{\mathrm{a}} \mathrm{S}_{\mathrm{BET}}=$ Specific surface area calculated by Brunauer-Emmett-Teller (BET) method

*Silica-Quercetin ratio 1:1=50 mg silica/50 mg quercetin; Silica—Quercetin ratio 1:5=10 mg silica/50 mg quercetin; Silica—Naringin ratio $1: 1=50 \mathrm{mg}$ silica $/ 50 \mathrm{mg}$ naringin; Silica-Naringin ratio $1: 5=10 \mathrm{mg}$ silica/50 $\mathrm{mg}$ naringin

SBA-15 was the material with the highest pore diameter, MSU-2 and HMS showed very similar $\mathrm{S}_{\mathrm{BET}}$ and pore volume values, which were significantly higher than the ones obtained for SBA-15 (Table 1). After the loading procedures, it was observed that in all cases the $S_{B E T}$ and pore volume of the three materials decreased (Table 1). This suggests that the polyphenols were successfully loaded inside the pores of the mesostructured silicas [52]. Besides of being loaded inside the pores, the decrease of the $S_{B E T}$ may also indicate that the analytes could be adsorbed as well on the surface of the materials by their interactions with the silanol groups of the silica surface. Likewise, the reduction in the $S_{B E T}$ and pore volume could be simply caused by the reduced mass fraction of silica in the polyphenol-silica composite. However, if the adsorption only happens on the external surface of the materials, the decrease of the $S_{B E T}$ would not be so noticeably, since much more surface is inside the mesopores. This fact is related to the reduction of the micropore area of the bare SBA-15 from $214 \mathrm{~m}^{2} \mathrm{~g}^{-1}$ to $184 \mathrm{~m}^{2} \mathrm{~g}^{-1}$ in the SBA15 loaded with naringin. Therefore, the results obtained suggest that adsorption of the analytes takes place in both sites of the materials, inside the mesopores and on the external surface. It was observed that the decrease of the $S_{B E T}$ and pore volume was more significant in the case of quercetin than in naringin. This may be due to the different molecular size of both flavonoids (see Electronic Supplementary Material (ESM) Fig. S1). Since naringin presents a higher width than quercetin, its entrance into the pore may be more hindered than in the case of quercetin. In the case of quercetin, the $S_{\mathrm{BET}}$ and pore volume were significantly more reduced with the silica/analyte ratio 1:5 than with the silica/analyte ratio 1:1. Conversely, for naringin slight differences were observed among both ratios (Table 1). The $S_{\mathrm{BET}}$ and pore volume are both determining parameters of the loading procedure since, as long as the pore size enables the analyte to get into the matrix, the higher the $\mathrm{S}_{\mathrm{BET}}$ and the pore volume, the greater the analyte loading will be [52]. In this sense, according to the results described in Sect. 3.1, HMS proved to be the material with the highest encapsulation efficiency of quercetin, probably due to its high $\mathrm{S}_{\mathrm{BET}}$ and great pore volume. Nevertheless, in the case of naringin, SBA-15 and MSU-2 showed the same encapsulation efficiency, while HMS was slightly less effective. This may be due to the bigger molecular size of naringin and the smaller pore diameter of HMS, which may hinder the entry of the analyte inside the pores. Conversely, the encapsulation of naringin was probably enhanced in the SBA-15 and MSU-2 because the pore diameter of these materials was higher than that of HMS.

\subsection{Preliminary release studies of quercetin and naringin loaded in SBA-15, MSU-2 and HMS mesostructured silicas}

After confirming the encapsulation procedure of quercetin and naringin in the mesostructured silicas, some initial preliminary release experiments were carried out with the silica/analyte ratios $1: 1$ and 1:5, whereas the silica/analyte ratio 
5:1 was discarded as it provided the lowest encapsulation efficiency, as it has been previously described in Sect. 3.1. Table 2 shows the release data of quercetin from the different mesostructured silicas at $\mathrm{pH} 7.0$ and 2.0. For SBA-15, although both ratios showed similar encapsulation efficiency, the release efficiency at $\mathrm{pH} 7.0$ was higher for the ratio 1:1 than for 1:5. Conversely, at $\mathrm{pH} 2.0$ the total amount released was greater in the ratio 1:5. With MSU-2, the encapsulation efficiency was also similar for both ratios. Nevertheless, as with SBA-15, the total amount released was significantly higher for silica/analyte ratio $1: 1$ at $\mathrm{pH} 7.0$, whereas at $\mathrm{pH}$ 2.0 it was greater for the silica/analyte ratio 1:5. In the case of HMS, despite the encapsulation efficiency was slightly higher for silica/analyte ratio 1:5, the total amount released was greater for silica/analyte ratio $1: 1$ at both $\mathrm{pH}$ values. Indeed, the differences observed in the release procedure among both ratios at $\mathrm{pH} 7.0$ were very little, but at $\mathrm{pH}$ 2.0 the silica/analyte ratio $1: 1$ was clearly more effective in the release of quercetin than the silica/analyte ratio 1:5.
Comparing the different materials, besides providing the greatest encapsulation \%, HMS was also the mesostructured silica which enabled to release the highest amount of quercetin at both $\mathrm{pH}$ values. Moreover, in all cases, the release of quercetin from the different materials was more effective at $\mathrm{pH} 2.0$ than at $\mathrm{pH}$ 7.0.

Regarding naringin, Table 3 lists its release data from the different mesostructured silicas at $\mathrm{pH} 7.0$ and 2.0. For SBA-15, both ratios showed similar encapsulation efficiency, but the silica/analyte ratio 1:5 provided a greater release of naringin than the silica/analyte ratio 1:1 at both $\mathrm{pHs}$ values. Moreover, the total amount released was very similar among the pHs tested. On the other hand, with MSU-2 the maximum encapsulation efficiency was similar at both ratios, but it was reached faster with silica/analyte ratio 1:5. Nevertheless, the release efficiency was significantly higher with silica/analyte ratio $1: 1$ at both $\mathrm{pHs}$, being slightly greater the total amount released at $\mathrm{pH}$ 7.0. For HMS, the maximum encapsulation efficiency was the same for both ratios.

Table 2 Release data of quercetin encapsulated in SBA-15, MSU-2 and HMS mesostructured silicas at pH 7.0 and 2.0 and optimum encapsulation time

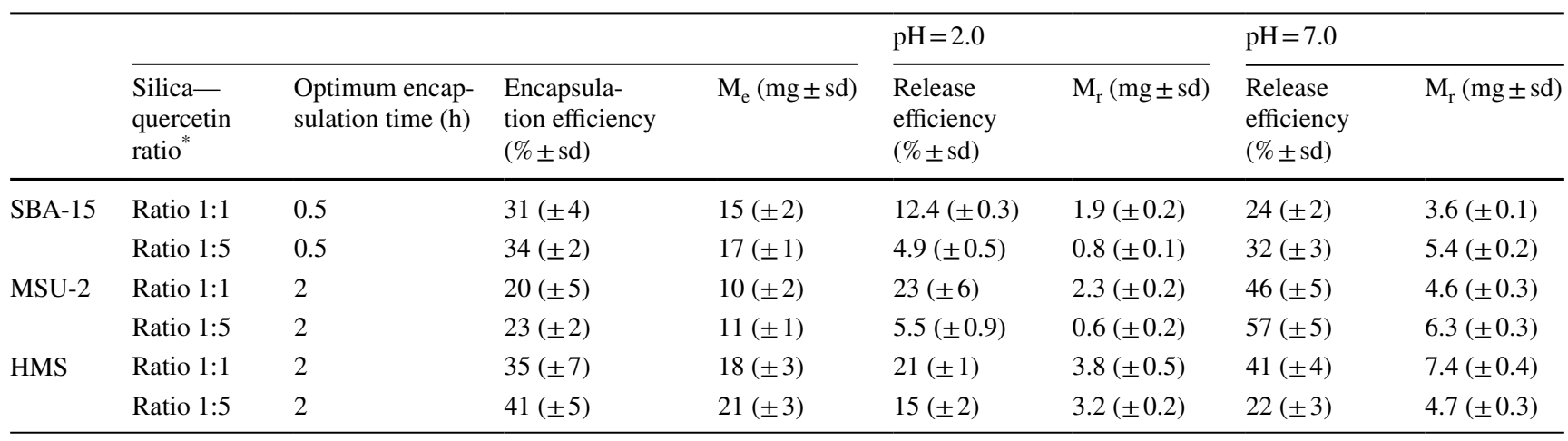

${ }^{*}$ Silica-quercetin ratio $1: 1=50 \mathrm{mg}$ silica/50 mg quercetin; Silica - quercetin ratio 1:5=10 mg silica/50 mg quercetin

$M_{e}$ Total amount (mg) of quercetin encapsulated, $M r$ Total amount (mg) of quercetin released at equilibrium

Table 3 Release data of naringin encapsulated in SBA-15, MSU-2 and HMS mesostructured silicas at pH 7.0 and 2.0 and optimum encapsulation time

\begin{tabular}{|c|c|c|c|c|c|c|c|c|}
\hline & \multirow[b]{2}{*}{$\begin{array}{l}\text { Silica-nar- } \\
\text { ingin ratio* }\end{array}$} & \multirow[b]{2}{*}{$\begin{array}{l}\text { Optimum encap- } \\
\text { sulation time (h) }\end{array}$} & \multirow[b]{2}{*}{$\begin{array}{l}\text { Encapsula- } \\
\text { tion efficiency } \\
(\% \pm s d)\end{array}$} & \multirow[b]{2}{*}{$\mathrm{M}_{\mathrm{e}}(\mathrm{mg} \pm \mathrm{sd})$} & \multicolumn{2}{|l|}{$\mathrm{pH}=7.0$} & \multicolumn{2}{|l|}{$\mathrm{pH}=2.0$} \\
\hline & & & & & $\begin{array}{l}\text { Release } \\
\text { efficiency } \\
(\% \pm \mathrm{sd})\end{array}$ & $\mathrm{M}_{\mathrm{r}}(\mathrm{mg} \pm \mathrm{sd})$ & $\begin{array}{l}\text { Release } \\
\text { efficiency } \\
(\% \pm s d)\end{array}$ & $\mathrm{M}_{\mathrm{r}}(\mathrm{mg} \pm \mathrm{sd})$ \\
\hline \multirow[t]{2}{*}{ SBA-15 } & Ratio 1:1 & 0.5 & $44( \pm 2)$ & $22( \pm 1)$ & $7.9( \pm 0.2)$ & $1.74( \pm 0.01)$ & $7.2( \pm 0.1)$ & $1.58( \pm 0.01)$ \\
\hline & Ratio 1:5 & 0.5 & $47( \pm 7)$ & $24( \pm 4)$ & $9( \pm 2)$ & $2.2( \pm 0.2)$ & $9( \pm 1)$ & $2.2( \pm 0.1)$ \\
\hline \multirow[t]{2}{*}{ MSU-2 } & Ratio 1:1 & 2 & $42( \pm 5)$ & $21( \pm 2)$ & $13.2( \pm 0.6)$ & $2.77( \pm 0.03)$ & $11( \pm 3)$ & $2.3( \pm 0.3)$ \\
\hline & Ratio 1:5 & 0.5 & $45( \pm 5)$ & $23( \pm 3)$ & $7( \pm 1)$ & $1.6( \pm 0.2)$ & $7.9( \pm 0.8)$ & $1.82( \pm 0.07)$ \\
\hline \multirow[t]{2}{*}{ HMS } & Ratio 1:1 & 1 & $40( \pm 3)$ & $20( \pm 2)$ & $9.1( \pm 0.3)$ & $1.8( \pm 0.1)$ & $8.1( \pm 0.2)$ & $1.62( \pm 0.01)$ \\
\hline & Ratio 1:5 & 0.5 & $40( \pm 2)$ & $20( \pm 1)$ & $12.5( \pm 0.7)$ & $2.5( \pm 0.2)$ & $12( \pm 1)$ & $2.4( \pm 0.2)$ \\
\hline
\end{tabular}

${ }^{*}$ Silica—naringin ratio $1: 1=50 \mathrm{mg}$ silica/50 mg naringin; Silica - naringin ratio 1:5=10 $\mathrm{mg}$ silica $/ 50 \mathrm{mg}$ naringin

Me total amount (mg) of naringin encapsulated, $M r$ Total amount (mg) of naringin released at equilibrium 
However, this maximum was achieved faster with silica/analyte ratio 1:5. Moreover, the ratio 1:5 also provided higher release efficiency than silica/analyte ratio $1: 1$ at both $\mathrm{pHs}$, and the total amount released was the same at $\mathrm{pH} 7.0$ and 2.0. Comparing the different materials at the highest release conditions for each of them, it was observed that the total amount released was very similar among them. However, also considering the encapsulation time and efficiency, both HMS and SBA-15 at a silica/analyte ratio 1:5 could be considered the most suitable materials to be used as naringin carriers.

\subsection{In vitro controlled release kinetics of quercetin and naringin loaded in HMS mesostructured silicas}

The in vitro controlled release of quercetin and naringin was performed to simulate the gastrointestinal conditions. These experiments were only carried out with HMS mesostructured silica, as it proved to be a suitable carrier for both quercetin and naringin. Moreover, HMS was the silica with the largest particle size as indicated in Sect. 3.2, thus it could be safer than SBA-15 and MSU-2 for developing orally administrated controlled release devices in order to avoid crossing epitheliums or being internalized by certain cells of the body [22, 59, 60]. Furthermore, the synthesis of HMS is more cost-effective and sustainable, in addition to providing thicker pore walls that improve and allow better access to the wormhole-like framework in adsorption processes [64] and confer more hydrothermal stability to the material avoiding any possible degradation inside the stomach. After the encapsulation procedure of the analytes in the silica using the optimum conditions previously established, the release studies were carried out with potassium chloride buffer at $\mathrm{pH} 2.0$ (simulating stomach conditions) and PBS at $\mathrm{pH} 7.4$ (simulating intestinal conditions) [22]. Figure 5a and $b$ show the release behaviour of quercetin from HMS loaded at different ratios under different $\mathrm{pH}$ conditions. As it is observed, the silica/analyte ratio 1:1 provided greater release efficiency of quercetin than the silica/analyte ratio 1:5 at both pHs tested. At $\mathrm{pH} 2.0$ the release efficiency of quercetin reached its stability after $15 \mathrm{~min}$ with the ratio 1:1, whereas for ratio $1: 5$ the highest release was achieved faster ( $5 \mathrm{~min})$ (Fig. 5a). In contrast, at $\mathrm{pH} 7.4$ the release efficiency of quercetin was lower than at $\mathrm{pH} 2.0$ for both ratios. The maximum release efficiency of quercetin at $\mathrm{pH} 7.4$ was achieved at $25 \mathrm{~min}$ and $15 \mathrm{~min}$ for silica/analyte ratios 1:1 and 1:5, respectively (Fig. 5b). These results agreed with the
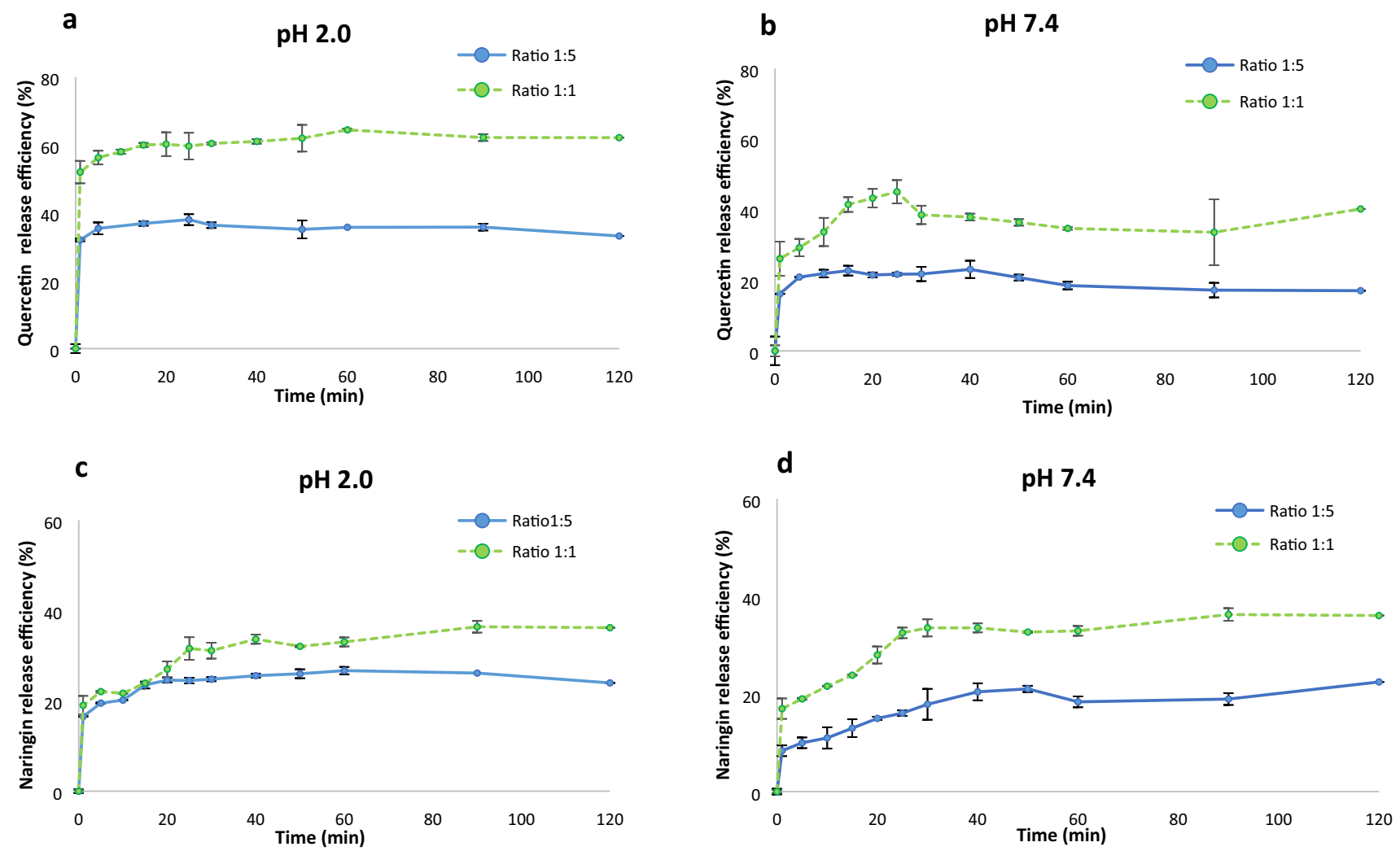

Fig. 5 Release kinetics under different $\mathrm{pH}$ conditions of quercetin $(\mathbf{a}, \mathbf{b})$ and naringin $(\mathbf{c}, \mathbf{d})$ loaded at different ratios from HMS mesostructured silica. Ratio $1: 1=50 \mathrm{mg}$ silica/50 $\mathrm{mg}$ analyte; ratio $1: 5=10 \mathrm{mg}$ silica/50 $\mathrm{mg}$ analyte 
preliminary release studies previously described. Therefore, although the ratio 1:5 slightly enabled higher encapsulation efficiency, it was less effective for the release of quercetin as the amount released was lower than with ratio 1:1. For this reason, it is important to evaluate not only the loading ability but also the release capability of the carrier under the actual application conditions.

On the other hand, Fig. 5c and d show the release behaviour of naringin from HMS loaded at different ratios under different $\mathrm{pH}$ conditions. As in the case of quercetin, the release efficiency of naringin was also higher with silica/ analyte ratio $1: 1$ at both $\mathrm{pH}$ conditions than with the silica/ analyte ratio $1: 5$. With the ratio $1: 1$, the release efficiency of naringin reached its stability after $25 \mathrm{~min}$ at both $\mathrm{pHs}$, and the amount released of naringin was almost the same with both $\mathrm{pH}$ values. Conversely, for ratio 1:5 the release efficiency of naringin reached its stability after $20 \mathrm{~min}$ at $\mathrm{pH} 2.0$, whereas at $\mathrm{pH} 7.4$ the maximum amount released of naringin was achieved after $40 \mathrm{~min}$ and was slightly lower than at $\mathrm{pH}$ 2.0. Thus, although in the preliminary release studies it seemed that the ratio 1:5 was more suitable, under gastrointestinal conditions it seemed more effective to use the ratio 1:1 for naringin loading in HMS.

Comparing the results of both flavonoids, it is observed that although the amount of each flavonoid loaded in the HMS silica is almost the same, the amount released of quercetin from the carrier is higher than the amount of naringin in all the conditions assayed. This may be due to the higher molecular size of naringin and the presence of its sugar moiety, which may hinder the release of the compound from inside the pores.

Additionally, the release kinetics of the analytes from the pores of the HMS silica at both $\mathrm{pHs}$ and different ratios were evaluated with the Higuchi model (Fig. 6). According to this model, for a purely diffusion-controlled process, a linear relationship is valid for the release of relatively small molecules distributed uniformly throughout the carrier [65, 66]. As it is observed in Fig. 6, all the system behaviors display a one-step linear release in the first minutes of the release process (15-50 min, Table S1). Therefore, the model fits well to the data suggesting that in these conditions the delivery of the analytes from the pores of the HMS silica is basically a diffusive process. Regarding both $\mathrm{pHs}$, the $\mathrm{K}_{\mathrm{H}}$ values are higher at $\mathrm{pH} 7.4$ than at $\mathrm{pH} 2.0$ (Table S1), implying slower release rate of the analyte from the pores at $\mathrm{pH}$ 2.0. At both $\mathrm{pHs}$, the silica/analyte ratio $1: 1$ for both analytes shows higher $\mathrm{K}_{\mathrm{H}}$ and release rate than the silica/analyte ratio 1:5 (Table S1). Moreover, at both $\mathrm{pHs}$ the release of quercetin is faster than the release of naringin, what may be due to the bigger size of naringin. It was also observed that in all cases the y-interception values were high (very superior to 0 value) (Fig. 6). This phenomenon is known as burst release, which refers to an initial massive release of the analyte that takes places immediately in the first minutes after placing the delivery system into the release medium [22]. Sometimes, the burst release can be desirable such as in the case of the encapsulation of aromas or for targeted release. Nevertheless, it is undesired for a sustained release.

\subsection{Antioxidant activity capacity of quercetin and naringin after their release from HMS mesostructured silica}

The antioxidant activity of the different quercetin and naringin encapsulates on HMS mesostructured silica was determined after their in-vitro controlled release at different $\mathrm{pH}$ conditions and silica/analyte ratios 1:1 and 1:5 in order to see if the encapsulation procedure improves their antioxidant efficacy. Figure 7 shows the antioxidant activity obtained for the quercetin and naringin encapsulated and non-encapsulated (control) samples. As it is observed, the antioxidant activity of quercetin was higher at $\mathrm{pH} 2.0$ than at $\mathrm{pH} 7.4$ for both silica/analyte ratios. Conversely, the antioxidant activity of naringin was significantly higher at $\mathrm{pH} 7.4$ than at $\mathrm{pH}$ 2.0 for both ratios. Nevertheless, although in all cases the antioxidant activity was higher for the encapsulated samples than for the non-encapsulated samples, a significant statistically increased of the antioxidant activity was only noticed at $\mathrm{pH} 7.4$ for quercetin (at both silica/analyte ratios) and $\mathrm{pH}$ 2.0 for naringin (at both silica/analyte ratios), as indicated by the increasing $\%$ of antioxidant activity (Fig. 7). These results suggest that both quercetin and naringin maintain more antioxidant activity when they are released from the carrier than when they are administrated free in the release medium, mainly at $\mathrm{pH} 7.4$ and 2.0, respectively. This suggests that the encapsulation procedure helps to keep the antioxidant activity of the analytes when they are released in the gastrointestinal tract. In contrast, the direct intake of these compounds in their free form negatively affect their antioxidant ability. Therefore, the encapsulation of these polyphenols in mesostructured silicas could be considered a potential way to protect the beneficial antioxidant properties of these compounds until their absorption and enhance their bioavailability.

\section{Conclusions}

Two mesostructured silicas with wormhole-like pore arrangement (HMS and MSU-2) and one hexagonal mesostructured SBA-15 silica type with different morphology and textural properties were successfully synthesized and evaluated as carriers for the encapsulation of two bioactive flavonoids (quercetin and naringin). The characterization of the materials before and after the encapsulation with the analytes confirmed that both flavonoids were successfully loaded inside the mesopores 
Fig. 6 Higuchi release profile under different $\mathrm{pH}$ conditions of quercetin and naringin delivered from HMS mesostructured silica at different silica/analyte ratios. Ratio $1: 1=50 \mathrm{mg}$ silica/50 $\mathrm{mg}$ analyte; ratio $1: 5=10 \mathrm{mg}$ silica/50 $\mathrm{mg}$ analyte
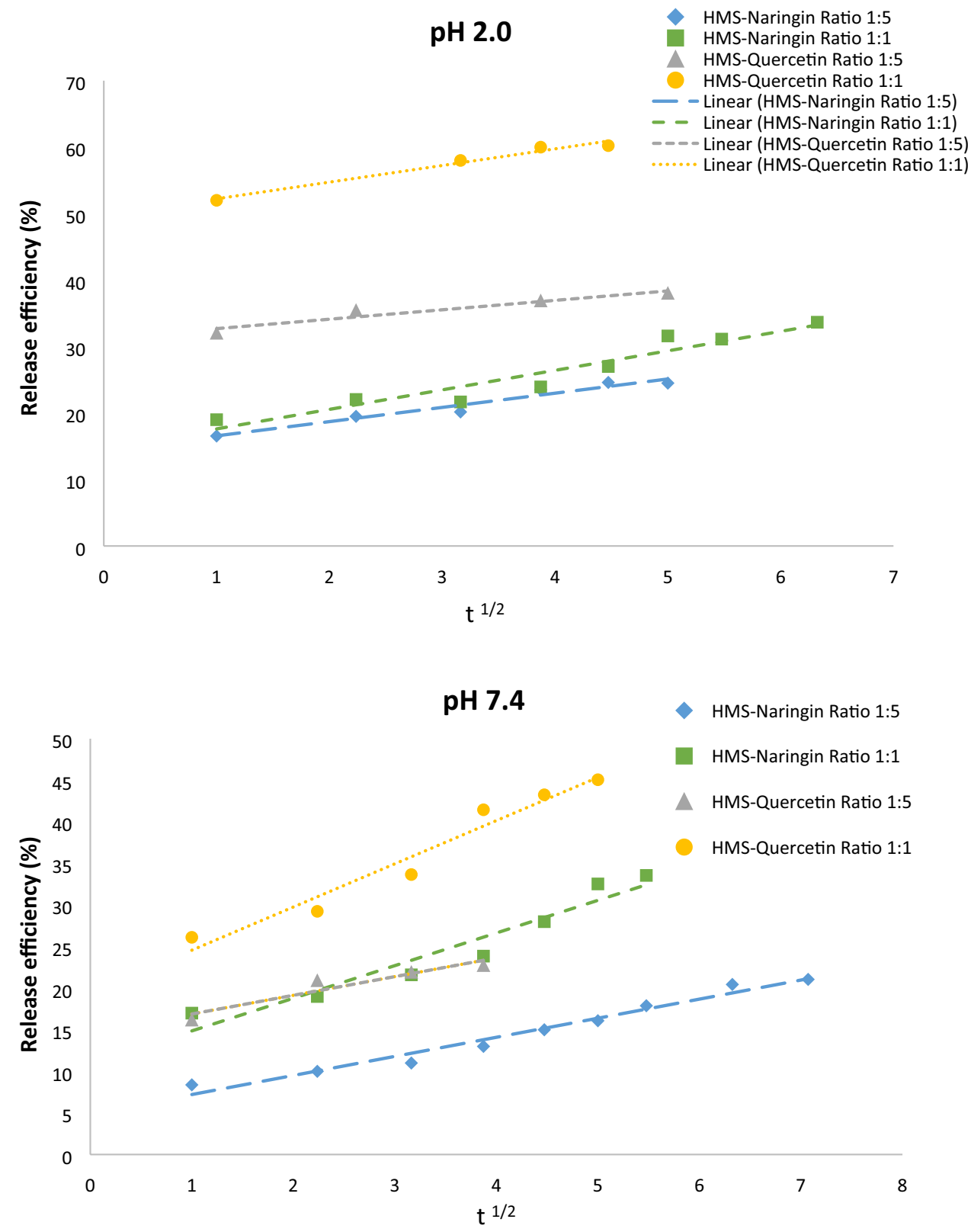

of the three silicas. Nevertheless, it was observed that these compounds were also adsorbed in the surface of the materials, due to their interactions with the silanol groups of the silicas surface. Thus, for future works it could be interesting to prepare end-capped materials or functionalized them with ligands which can act as molecular gates to achieve a more specific and controlled encapsulation of the analytes. Different silica/analyte ratios were evaluated to determine the loading and encapsulation kinetics of the different materials tested. The ratio 1:5 seemed the most suitable, as it provided, in general, the highest encapsulation efficiency and loading capacity of the analytes using the least amount of silica. Regarding the different materials, HMS showed higher loading capacity of quercetin than SBA-15 and MSU-2, whereas for naringin
SBA-15 and MSU-2 were slightly more effective. These differences could be attributed to the molecular size of the analytes and the textural properties of the different materials. Nevertheless, HMS resulted to be the silica which enabled to release the highest amount of both analytes. Thus, this silica could be considered a suitable carrier of these flavonoids and an alternative to other mesostructured materials frequently used as encapsulating supports, such as SBA-15. The release process was also performed under controlled conditions to simulate the digestive process. quercetin was released faster and more efficiently at $\mathrm{pH}$ 2.0, whereas no differences were observed for naringin at both $\mathrm{pHs}$ tested. Despite the encapsulation efficiency of the analytes was higher with the silica/analyte ratio $1: 5$, the release process was more suitable with silica/ 
Fig. 7 Antioxidant activity obtained for the quercetin and naringin encapsulated into HMS mesostructured silica and released under optimized condi(control) samples (the analyte is directly added into the release medium) at different silica/analyte ratios and $\mathrm{pHs}$ conditions. Increasing $\%$ of antioxidant activity: (Antioxidant activity encapsulated samples - Antioxidant activity control samples)/ Antioxidant activity encapsulated samples $\times 100$ tions and non-encapsulated

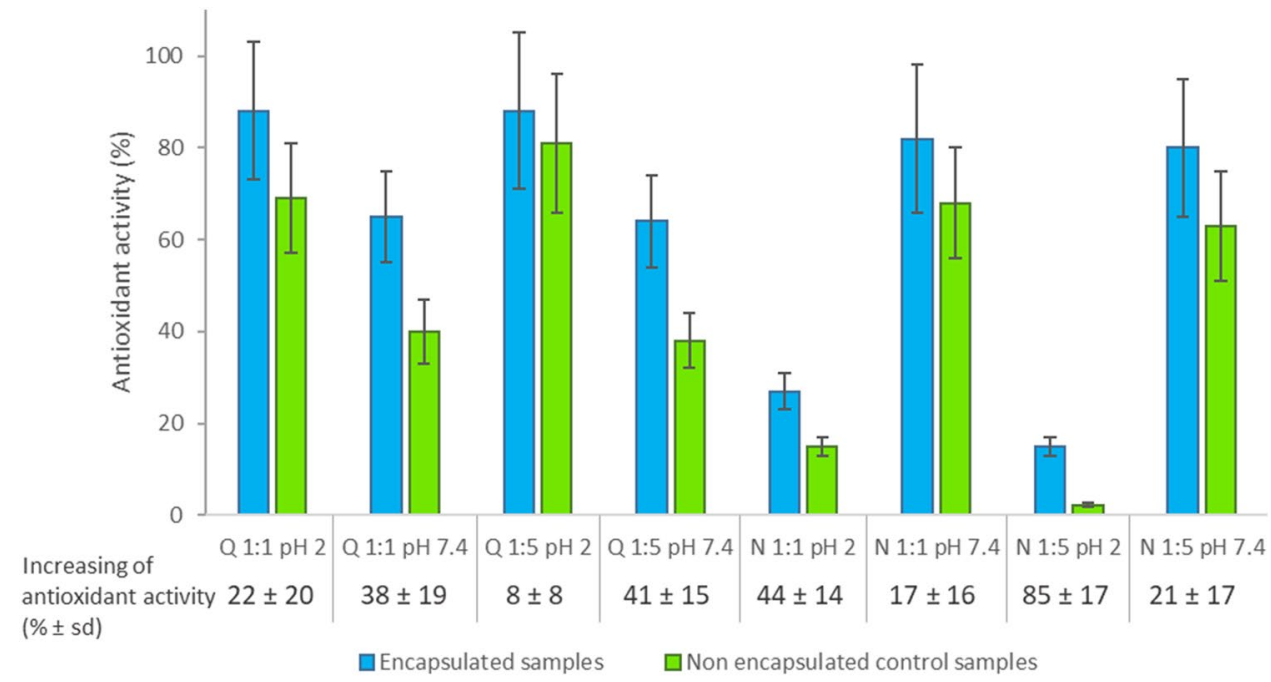

analyte ratio 1:1 for both analytes, as a higher amount of them was released with this ratio under gastrointestinal conditions. The antioxidant activity of the resulting encapsulated was also determined, confirming that the encapsulation procedure helps to maintain the antioxidant activity of the analytes better than being directly administrated in their free form. Therefore, this preliminary work shows that wormhole-like pore mesostructured silicas, such as HMS, could be considered as carriers to protect the stability and antioxidant properties of these compounds until their absorption and enhance their bioavailability, so they can potentially be used in future food and biomedical applications. Nevertheless, future works should also further explore the cytotoxicity and stability of this material.

Supplementary Information The online version contains supplementary material available at https://doi.org/10.1007/s10934-021-01144-7.

Acknowledgements This work was supported by the Comunidad de Madrid and European funding from FSE and Feder programs (project S2018/BAA-4393, AVANSECAL-II-CM).

Author contributions SM-Z and IS contributed to the study conception and design. Material preparation, data collection and analysis were performed by AE, DP-Q and SM-Z. The first draft of the manuscript was written by $\mathrm{NC}, \mathrm{AE}$ and $\mathrm{SM}-\mathrm{Z}$ and all authors commented on previous versions of the manuscript. All authors read and approved the final manuscript. Supervision: SM-Z, DP-Q and IS. Funding acquisition and resources: IS.

Funding Open Access funding provided thanks to the CRUE-CSIC agreement with Springer Nature.

\section{Declarations}

Conflict of interest Authors declare no conflict of interests.

Open Access This article is licensed under a Creative Commons Attribution 4.0 International License, which permits use, sharing, adaptation, distribution and reproduction in any medium or format, as long as you give appropriate credit to the original author(s) and the source, provide a link to the Creative Commons licence, and indicate if changes were made. The images or other third party material in this article are included in the article's Creative Commons licence, unless indicated otherwise in a credit line to the material. If material is not included in the article's Creative Commons licence and your intended use is not permitted by statutory regulation or exceeds the permitted use, you will need to obtain permission directly from the copyright holder. To view a copy of this licence, visit http://creativecommons. org/licenses/by/4.0/.

\section{References}

1. A. Scalbert, C. Manach, C. Morand, C. Remesy, L. Jimenez, Crit. Rev. Food Sci. Nutr. 45, 287 (2005)

2. D. Del Río, A. Rodriguez-Mateos, J. Spencer, M. Tognolini, G. Borges, A. Crozier, Antioxid. Redox Sign. 18, 1818 (2013)

3. P. Lucci, J. Saurina, O. Núñez, TrAC 88, 1 (2017)

4. G.H. Lee, S.J. Lee, S.W. Jeong, H.C. Kim, G.Y. Park, S.G. Lee, J.H. Choi, Colloid. Surface B 143, 511 (2016)

5. M.R. Lauro, F. De Simone, F. Sansone, P. Iannelli, R.P. Aquino, J. Drug Del. Sci. Tech. 17, 119 (2007)

6. R.G. Budel, D.A. da Silva, M.P. Moreira, A.J.F. Dalcin, A.F. da Silva, L.R. Nazario, J.H. Majolo, L.Q.S. Lopes, R.C.V. Santos, F.A.A. Soares, R.S. da Silva, P. Gomes, C.R. Boeck, Colloid Surf. B 188, 1104 (2020)

7. F. Sansone, P. Picerno, T. Mencherini, F. Villecco, A.M. D'ursi, R.P. Aquino, M.R. Lauro, J. Food Eng. 103, 188 (2011)

8. M. Popova, I. Trendafilova, Á. Szegedi, J. Mihály, P. Németh, S.G. Marinova, H.A. Aleksandrov, G.N. Vayssilov, Micropor. Mesopor. Mat. 228, 256 (2016)

9. A.F. Esfanjani, S.M. Jafari, Colloid. Surface. B 146, 532 (2016)

10. A. Priprem, J. Watanatorn, S. Sutthiparinyanont, W. Phachonpai, S. Muchimapura, Nanomed. 4, 70 (2008)

11. Y. Zhang, Y. Yang, K. Tang, X. Hu, G. Zou, J. Appl. Polym. Sci. 107, 891 (2008)

12. R. Fang, H. Jing, Z. Chai, G. Zhao, S. Stoll, F. Ren, F. Liu, X. Leng, J. Nano-biotech. 9, 9 (2011)

13. R. Fang, R.F. Hao, X. Wu, Q. Li, X.J. Leng, H. Jing, J. Agric. Food Chem. 59, 6292 (2011) 
14. A.R. Patel, P.C.M. Heussen, J. Hazekamp, E. Drost, K.P. Velikov, Food Chem. 133, 423 (2012)

15. H.K. Ha, J.W. Kim, M.R. Lee, W.J. Lee, Food Res. Int. 52, 82 (2013)

16. D.A. Pai, V.R. Vangala, J.W. Ng, W.K. Ng, R.B. Tan, J. Food Eng. 161, 68 (2015)

17. L. Cui, Z.H. Zhang, E. Sun, X.B. Jia, Int. J. Mol. Sci. 13, 14251 (2012)

18. S. Sapino, E. Ugazio, L. Gastaldi, I. Miletto, G. Berlier, D. Zonari, S. Oliaro-Bosso, Eur. J. Pharm. Biopharm. 89, 116 (2015)

19. C.M. Nday, E. Halevas, G.E. Jackson, A. Salifoglou, J. Inorg. Biochem. 145, 51 (2015)

20. Y. Li, X. Zhao, Y. Zu, L. Wang, W. Wu, Y. Deng, C. Zu, Y. Liu, Eur. J. Pharm. Biopharm. 112, 58 (2017)

21. M. Ruiz-Rico, H. Daubenschüz, É. Pérez-Esteve, M.D. Marcos, P. Amorós, R. Martínez-Máñez, J.M. Barat, Eur. J. Pharm. Biopharm. 105, 9 (2016)

22. É. Pérez-Esteve, M. Ruiz-Rico, C. de la Torre, L.A. Villaescusa, F. Sancenón, M.D. Marcos, P. Amorós, R. Martínez-Máñez, J.M. Barat, Food Chem. 196, 66 (2016)

23. M. Ruiz-Rico, É. Pérez-Esteve, M.J. Lerma-García, M.D. Marcos, R. Martínez-Máñez, J.M. Barat, Food Chem. 218, 471 (2017)

24. É. Pérez-Esteve, M. Ruiz-Rico, A. Fuentes, M.D. Marcos, F. Sancenón, R. Martínez-Máñez, J.M. Barat, LWT-Food Sci. Tech. 72, 351 (2016)

25. G. Berlier, L. Gastaldi, S. Sapino, I. Miletto, E. Bottinelli, D. Chirio, E. Ugazio, Int. J. Pharm. 457, 177 (2013)

26. L. Gastaldi, E. Ugazio, S. Sapino, P. Iliade, I. Miletto, G. Berlier, Phys. Chem. Chem. Phys. 14, 11318 (2012)

27. Z. Li, J.C. Barnes, A. Bosoy, J.F. Stoddart, J.I. Zink, Chem. Soc. Rev. 41, 2590 (2012)

28. M. Manzano, M. Colilla, M. Vallet-Regí, Expert Opin. Drug Deliv. 6, 1383 (2009)

29. D. Brevet, O. Hocine, A. Delalande, L. Raehm, C. Charnay, P. Midoux, Int. J. Pharm. 471, 197 (2014)

30. J.M. Rosenholm, V. Mamaeva, C. Sahlgren, M. Linden, Nanomed. 7, $111(2012)$

31. J. Vivero-Escoto, I. Slowing, B. Trewyn, V. Lin, Small 18, 1952 (2010)

32. Y. Choudhari, H. Hoefer, C. Libanati, F. Monsuur, W. McCarthy, in Amorphous solid dispersions, ed. By N. Shah, H. Sandhu, D.S. Choi, H. Chokshi, A.W. Malick (Springer, New York, 2014) p. 665

33. F. Hoffmann, M. Cornelius, J. Morell, M. Fröba, Angew. Chem. Int. Ed. 45, 3216 (2006)

34. I. Sierra, D. Pérez-Quintanilla, Chem. Soc. Rev. 42, 3792 (2013)

35. N. Casado, D. Pérez-Quintanilla, S. Morante-Zarcero, I. Sierra, TrAC 88, 167 (2017)

36. N. Summerlin, Z. Qu, N. Pujara, Y. Sheng, S. Jambhrunkar, M. McGuckin, A. Popat, Colloid. Surface. B 144, 1 (2016)

37. M. Popova, A. Szegedi, V. Mavrodinova, N.N. Tušar, J. Mihály, S. Klébert, N. Benbassat, K. Yoncheva, J. Solid State Chem. 219, 37 (2014)

38. C.T. Kresge, M.E. Leonowicz, W.J. Roth, J.C. Vartuli, J.S. Beck, Nature 359, 710 (1992)

39. J.S. Beck, J.C. Vartuli, W.J. Roth, M.E. Leonowicz, C.T. Kresge, K.D. Schmitt, C.T. Chu, D.H. Olson, E.W. Sheooard, J. Am. Chem. Soc. 114, 10834 (1992)

40. P.M. Visakh, M.J. Martínez Morlanes, Nanomaterials and Nanocomposites: Zero-to Three-Dimensional Materials and Their Composites (Wiley, Weinheim, 2016), pp. 223-252

41. G. Berlier, L. Gastaldi, E. Ugazio, I. Miletto, P. Iliade, S. Sapino, J. Colloid Interf. Sci. 393, 109 (2013)
42. I. Trendafilova, Á. Szegedi, J. Mihály, G. Momekov, N. Lihareva, M. Popova, Mater. Sci. Eng. C 73, 285 (2017)

43. K.E.A. AbouAitah, A.A. Farghali, A. Swiderska-Sroda, W. Lojkowski, A.M. Razin, M.H. Khedr, J. Nanomed. Nanotech. 7, 1 (2016)

44. W. Zhang, T.R. Pauly, T.J. Pinnavaia, Chem Mat. 9, 2491 (1997)

45. D. Pérez-Quintanilla, A. Sánchez, I. del Hierro, M. Fajardo, I. Sierra, J. Sep. Sci. 30, 1556 (2007)

46. N. Nandan, T.S. Saini, A. Kumar, R.K. Sinha, Int. Soc. Optics Photonics 9544, 95441D (2015)

47. É. Prouzet, C. Boissière, C. R. Chim. 8, 579 (2005)

48. D. Zhao, Q. Huo, J. Feng, B.F. Chmelka, G.D. Stucky, J. Am. Chem. Soc. 120, 6024 (1998)

49. D. Pérez-Quintanilla, A. Sánchez, I. del Hierro, M. Fajardo, I. Sierra, J. Nanosci. Nanotechnol. 9, 4901 (2009)

50. D. Pérez-Quintanilla, A. Sánchez, I. del Hierro, M. Fajardo, I. Sierra, Microchim. Acta 165, 291 (2009)

51. W. Brand-Williams, M.E. Cuvelier, C. Berset, Food Sci. Technol 28, 25 (1995)

52. L. Sun, L. Lu, X. Qiu, Y. Tang, Food Control 71, 193 (2017)

53. DIRECTIVE 2009/32/EC OF THE EUROPEAN PARLIAMENT AND OF THE COUNCIL of 23 April 2009 on the approximation of the laws of the Member States on extraction solvents used in the production of foodstuffs and food ingredients. https://eur-lex. europa.eu/legal-content/EN/TXT/PDF/?uri=CELEX:32009L0032 $\&$ from $=$ EN. Accessed 14 May 2020.

54. COMMISSION DIRECTIVE 2010/59/EU of 26 August 2010 amending Directive 2009/32/EC of the European Parliament and of the Council on the approximation of the laws of the Member States on extraction solvents used in the production of foodstuffs and food ingredients. https://eur-lex.europa.eu/LexUriServ/LexUr iServ.do?uri=OJ:L:2010:225:0010:0012:EN:PDF. Accessed 14 May 2020.

55. S.S. Hu, W. Cao, J.H. Da, H.B. Dai, J. Cao, L.H. Ye, X.Y. Li, C. Chu, Food Anal. Methods. 8, 833 (2015)

56. S.S. Hu, W. Cao, H.B. Dai, J.H. Da, L.H. Ye, J. Cao, X.Y. Li, J. Agric. Food Chem. 62, 8822 (2014)

57. N. Casado, S. Morante-Zarcero, D. Pérez-Quintanilla, J.S. Câmara, I. Sierra, J. Agric. Food Chem. 67, 955 (2018)

58. D.M. Oliveira, A.S. Andrada, Cerâmica 65, 170 (2019)

59. D. Arcos, M. Vallet-Regí, Bioceramics for drug delivery. Acta Mater 61, 890 (2013)

60. É. Pérez-Esteve, M. Ruiz-Rico, C. de la Torre, E. Llorca, F. Sancenón, M.D. Marcos, P. Amorós, C. Guillem, R. Martínez-Máñez, J.M. Barat, Micropor. Mesopor. Mater. 230, 196 (2016)

61. S. Kumar, M.M. Malik, R. Purohit, Materials Today: Proceedings 4, 350 (2017)

62. D. Perez-Quintanilla, I. del Hierro, M. Fajardo, I. Sierra, J. Environ. Monitor. 8, 214 (2006)

63. J. Gañán, S. Morante-Zarcero, D. Pérez-Quintanilla, I. Sierra, Anal. Methods 7, 4740 (2015)

64. N. Casado, D. Pérez-Quintanilla, S. Morante-Zarcero, I. Sierra, Microchim. Acta 186, 164 (2019)

65. D. Suvakanta, N. Padala, N. Lilakanta, C. Prasanta, Acta Poloniae Pharmaceutica Drug Res 67, 217 (2010)

66. W. Guo, Ch. Yang, L. Cui, H. Lin, F. Qu, Langmuir 30, 243 (2014)

Publisher's Note Springer Nature remains neutral with regard to jurisdictional claims in published maps and institutional affiliations. 